\author{
UNIVERSIDADE DE SÃO PAULO \\ Faculdade de Ciências Farmacêuticas \\ Programa de Pós-Graduação em Ciências dos Alimentos \\ Área de Bromatologia
}

\title{
ESTUDO DA COMPOSIÇÃO VOLÁTIL E QUÍMICA DOS VINHOS DA VARIEDADE SYRAH DE DUAS REGIÕES DO SUDESTE BRASILEIRO, ELABORADOS EM CICLO DE INVERNO.
}

Lucas Bueno do Amaral

Dissertação para obtenção do Título de Mestre Orientador: Professor Doutor Eduardo Purgatto

São Paulo 


\author{
UNIVERSIDADE DE SÃO PAULO \\ Faculdade de Ciências Farmacêuticas \\ Programa de Pós-Graduação em Ciências dos Alimentos \\ Área de Bromatologia
}

\title{
ESTUDO DA COMPOSIÇÃO VOLÁTIL E QUÍMICA DOS VINHOS DA VARIEDADE SYRAH DE DUAS REGIÕES DO SUDESTE BRASILEIRO, ELABORADOS EM CICLO DE INVERNO.
}

\author{
Lucas Bueno do Amaral \\ Versão Original \\ Dissertação para obtenção do Título de Mestre \\ Orientador: Professor Doutor Eduardo Purgatto
}

São Paulo 
Lucas Bueno do Amaral

\section{ESTUDO DA COMPOSIÇÃO VOLÁTIL E QUÍMICA DOS VINHOS DA VARIEDADE SYRAH DE DUAS REGIÕES DO SUDESTE BRASILEIRO ELABORADOS EM CICLO DE INVERNO.}

Comissão Julgadora da dissertação para obtenção do Título de Mestre

$$
\begin{aligned}
& \text { Professor Dr. Eduardo Purgatto } \\
& \text { Orientador }
\end{aligned}
$$

1‥ Examinador

$2^{\circ}$. Examinador

3‥ Examinador

4ํ․ Examinador

São Paulo, de de 202 
Ficha Catalográfica

Elaborada pela Divisão de Biblioteca e Documentação do Conjunto das Químicas da USP

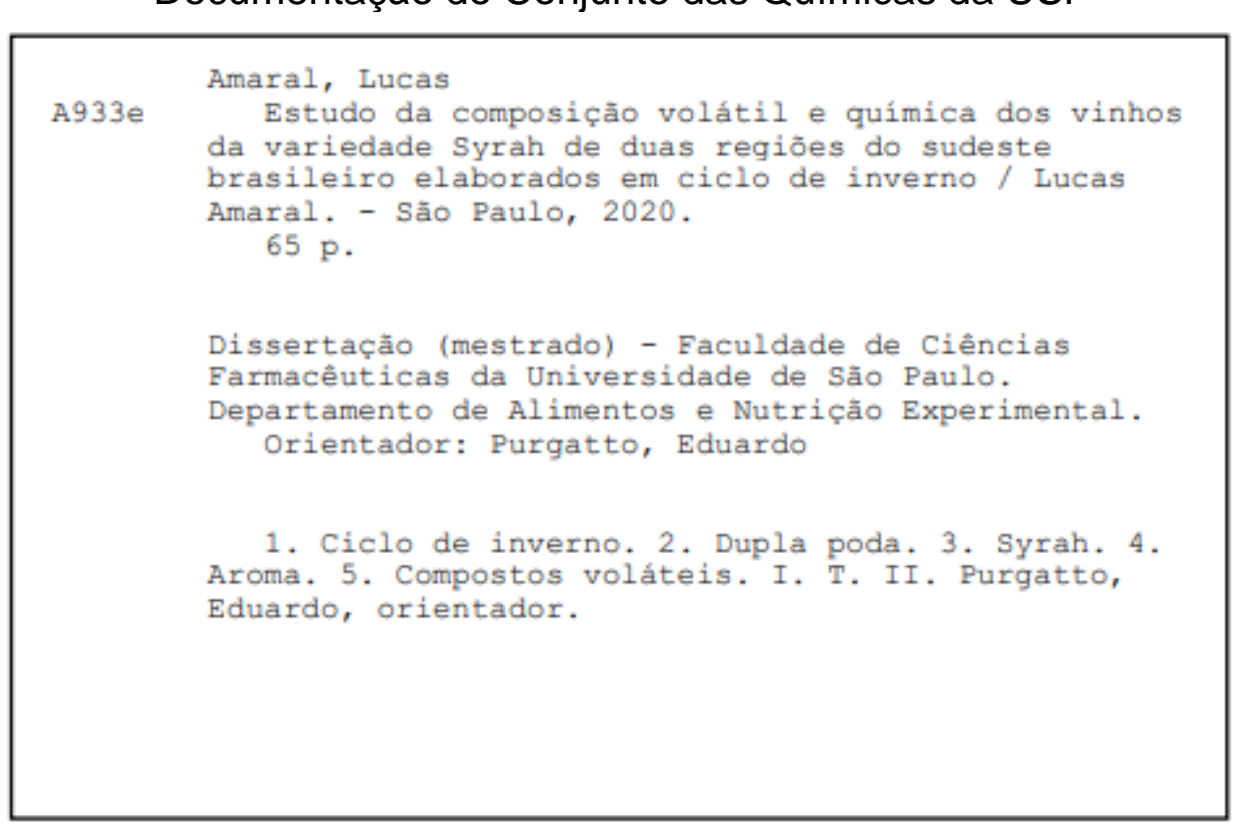




\section{Sumário}

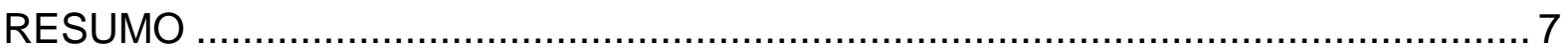

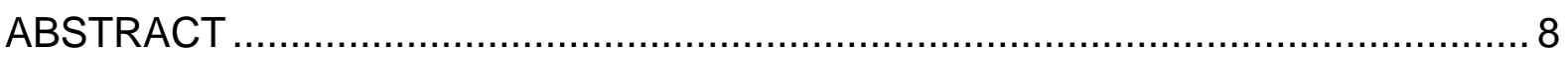

1- INTRODUÇÃO

1.1 Ciclo extemporâneo de inverno .............................................................. 13

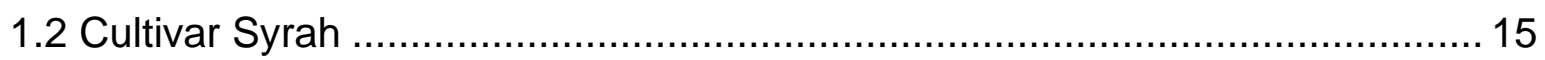

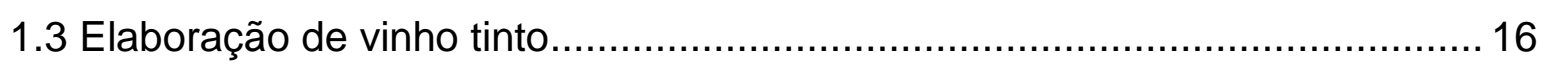

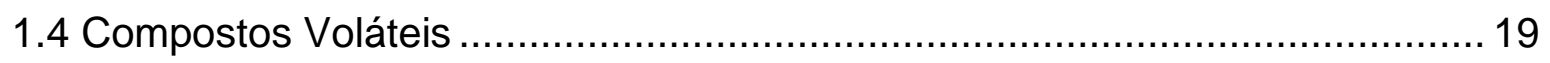

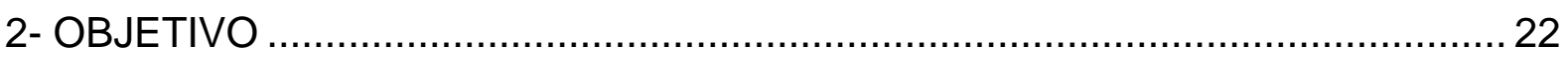

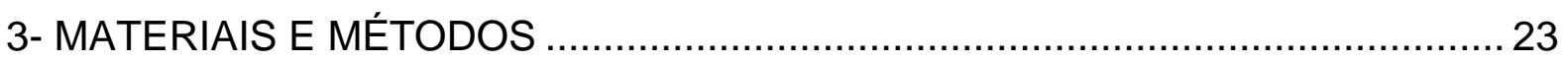

3.1 - Matéria prima e condições edafoclimáticas .............................................. 23

3.2 - Acompanhamento da maturação e Colheita ............................................. 24

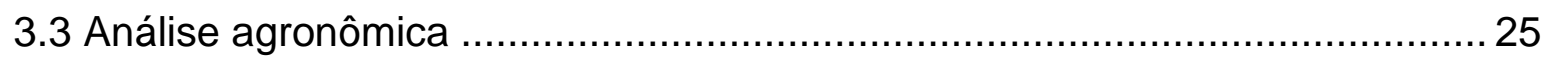

3.4 Microvinificação .............................................................................. 25

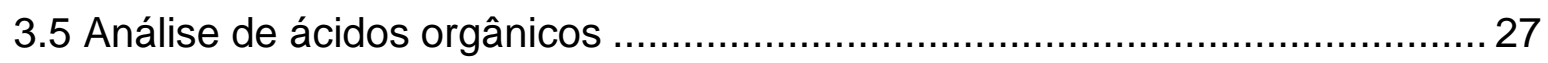

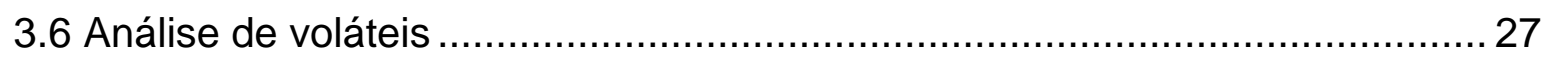

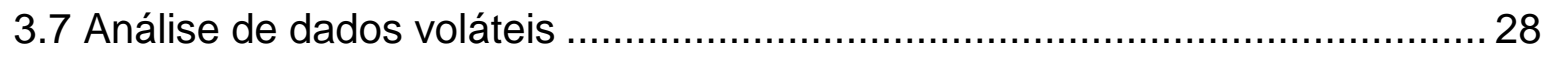

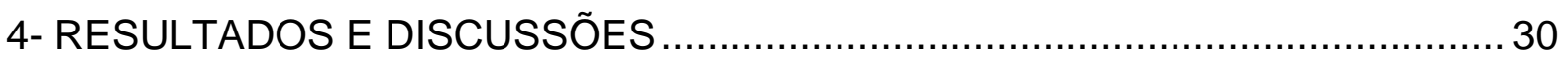

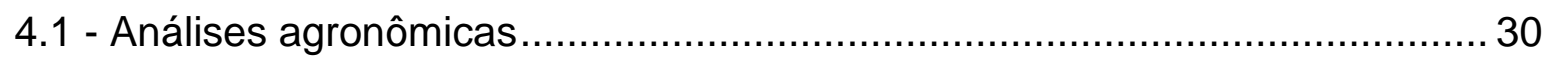

4.2 - ANÁLISE DE COMPOSTOS VOLATEIS …..................................................... 33

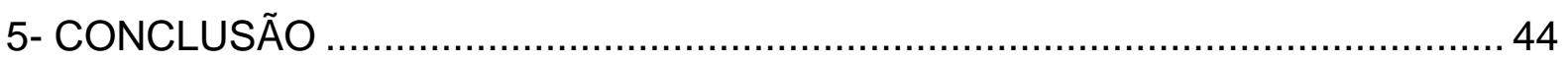

6- ANEXOS:

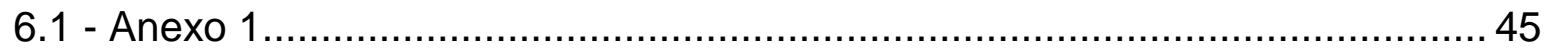

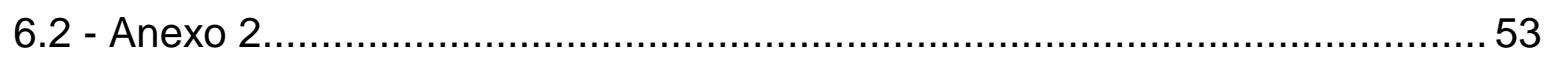

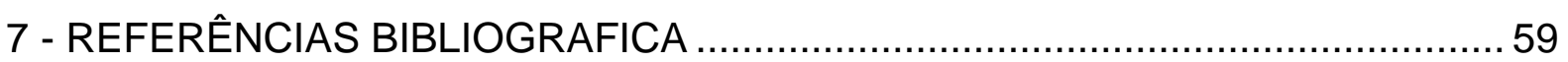




\section{Lista de figuras:}

Figura 1: Regiões produtoras do estado de São Paulo, destacando regiões tradicionais, regiões emergentes e Serra da Mantiqueira.

Figura 2: Ciclo extemporâneo de produção de uva.

Figura 4: Fluxograma de elaboração de vinho tinto pelo método tradicional.

Figura 5: Principais precursores e vias de formação de compostos voláteis

Figura 6: Regiões de São Bento do Sapucaí (5A) e Indaiatuba (5B)

Figura 7: Variedade Syrah sob ciclo de inverno em São Bento do Sapucaí (6A) e Indaiatuba (6B).

Figura 8: Processo de fermentação alcoólica em recipientes de vidro de 25 litros com variedades Syrah das regiões de São Bento do Sapucaí (7A) e Indaiatuba (7B).

Figura 9: Score plot discriminativo como componente principal o mosto a diferença entre regiões na região de São Bento do Sapucaí e Indaiatuba na safra de 2017.

Figura 10: Score plot discriminativo como componente principal o mosto a diferença entre regiões na região de São Bento do Sapucaí e Indaiatuba na safra de 2018.

Figura 11: Score plot discriminativo como componente principal o envase a diferença entre regiões na região de São Bento do Sapucaí e Indaiatuba na safra de 2017.

Figura 12: Score plot discriminativo como componente principal o envase a diferença entre regiões na região de São Bento do Sapucaí e Indaiatuba na safra de 2018.

Figura 13: Score plot discriminativo como componente principal o envelhecimento a diferença entre regiões na região de São Bento do Sapucaí e Indaiatuba na safra de 2017.

Figura 14: Score plot discriminativo como componente principal o envelhecimento a diferença entre regiões na região de São Bento do Sapucaí e Indaiatuba na safra de 2018.

Figura 15: Análise qualitativa dos compostos ao longo do processo de elaboração nas regiões de São Bento do Sapucaí e Indaiatuba na safra de 2017 e 2018. 


\section{Lista de tabelas:}

Tabela 1: Produção nacional de uva nos principais estados produtores brasileiros nos anos de 2013 à 2016, em toneladas.

Tabela 2: Análise agronômica das regiões de São Bento do Sapucaí e Indaiatuba, safras 2017 e 2018.

Tabela 3: Análise química do mosto das regiões de São Bento do Sapucaí e Indaiatuba, safras 2017 e 2018.

Tabela 4 Compostos voláteis identificados por classes nas etapas de elaboração do vinho com os respectivos CAS, código, nome do composto, descritor aromático (Análise por HS-SPME/GC-MS). Realizado na safra de 2017 e 2018 nas regiões de São Bento do Sapucaí (SB) e Indaiatuba (IN). 


\section{RESUMO}

AMARAL, Lucas Bueno do. Estudo da composição volátil e química dos vinhos da variedade Syrah de duas regiões do Sudeste brasileiro, elaborados em ciclo de inverno. 2020. Exame de Defesa (Mestrado em Ciências dos Alimentos - Área: Bromatologia) - Departamento de Alimentos e Nutrição Experimental - FCF, Universidade de São Paulo, São Paulo, 2020.

Compreender como uma variedade em particular pode contribuir no processo de vinificação é essencial para a elaboração de vinhos de alta qualidade. O conhecimento mais profundo das diversas estruturas presentes na uva e os mecanismos de sua evolução durante a vinificação são base indispensável na avaliação do papel da variedade em enologia e no desenvolvimento de processos tecnológicos adaptados ao potencial da matéria prima e ao tipo de produto desejado. Com isso, este trabalho visa identificar os aromas produzidos em cada etapa do processo de elaboração e de envelhecimento em garrafa e as características agronômicas da produção. $O$ experimento foi realizado em dois vinhedos comerciais do interior de São Paulo, utilizando a cultivar Syrah sob dupla poda e ciclo invertido de produção. Foram analisadas as principais etapas de produção: mosto, fermentações alcoólica e malolática, envase, 6 e 12 meses de envelhecimento das duas safras entre 2017 e 2018, através das técnicas de HPLC e GC-MS. Foram identificados aproximadamente 100 compostos voláteis, entre álcoois, terpenos, ésteres, fenóis, aldeídos, cetonas e outros. Dentre esses compostos destacam-se os descritores aromáticos de especiarias (Terpinen-4-ol) e tabaco ( $\beta$-Damascenone), comumente encontrados em vinhos Syrah de outras regiões. $O$ experimento mostra que existe uma diferença entre as duas regiões e entre as duas safras.

Palavras-chaves: Ciclo de inverno - dupla poda - Syrah - aroma - compostos voláteis - São Paulo. 


\section{ABSTRACT}

AMARAL, Lucas Bueno do. Study of the volatile and chemical composition of Syrah variety wines from two regions of southeast Brazil, produced in the winter cycle. 2020. Defense Exam (Master in Food Sciences - Area: Bromatology) Department of Food and Experimental Nutrition - FCF, University of São Paulo, São Paulo, 2020.

Understanding how a particular variety can contribute to the winemaking process is essential for making high quality wines. The deeper knowledge of the various structures present in the grape and the mechanisms of its evolution during winemaking are an indispensable basis in assessing the role of the variety in oenology and in the development of technological processes adapted to the potential of the raw material and the type of product desired. With this, this work aims to identify the aromas produced in each stage of the elaboration process and bottle aging and the grapes agronomic characteristics. The experiment was carried out in two commercial vineyards in the interior of São Paulo, using the cultivar Syrah under double pruning management and inverted production cycle. The main stages of production were analyzed: must, alcoholic and malolactic fermentations, bottling and 6 and 12 months aging, for both harvests between 2017 and 2018, using HPLC and GC-MS techniques. Approximately 100 volatile compounds have been identified, including alcohols, terpenes, esters, phenols, aldehydes, ketones and others. Among these compounds the aromatic descriptors of spices (Terpinen-4-ol) and tobacco ( $\beta$-Damascenone) stand out, commonly found in Syrah wines from other regions. The experiment shows that there is a difference between the two regions and between the two crops.

Keywords: Winter cycle - double pruning - Syrah - aroma - volatile compounds - São Paulo. 


\section{1- INTRODUÇÃO}

A vitivinicultura brasileira é muito recente quando comparada às tradicionais regiões produtoras do mundo. O cultivo da videira chegou ao país com os imigrantes portugueses no século XVI e tornou-se uma atividade comercial a partir do século XX, influenciada também pela imigração italiana e alemã, (CAMARGO et al., 2011; PROTAS et al., 2006) sendo difundida principalmente nas regiões Sul, Sudeste e Nordeste do país. Os cultivos nestas regiões vêm se atualizando e se desenvolvendo com o passar dos anos, pois a vitivinicultura adquiriu um papel importante na economia destes estados (BNDES, 2004).

No Sudeste brasileiro, a história da videira se confunde com a chegada dos portugueses no Brasil, pois foi na capitania de São Vicente, hoje São Paulo (IBRAVIN, 2016), que as primeiras uvas Vitis vinifera L. foram plantadas. Porém, nas primeiras décadas do século XIX, com a introdução de variedades de uvas procedentes da América do Norte (Vitis labrusca L.), foi introduzida a filoxera, doença que ataca as raízes das videiras, levando a morte da planta. Essa doença levou a viticultura colonial à decadência.

Após algumas décadas, em meados do século XX, o panorama da viticultura paulista mudou significativamente com a substituição da cultivar Isabel pela cultivar Niágara Branca e Seibel 2. Essas mudanças, aliadas ao surgimento das novas técnicas de produção e ao aperfeiçoamento agrícola no plantio da uva, colocaram o estado de São Paulo entre os maiores produtores de vinho comum em apenas 40 anos (SANTOS, 1938). Esta realidade mudou com o passar dos anos; apesar do estado ser grande produtor de uvas para consumo in natura, sua produção de uvas para processamento é pequena e a maior parte da uva usada para a elaboração de vinhos, sejam estes finos ou comuns, são trazidas do Rio Grande do Sul. Apesar de 
São Paulo historicamente ter sido o estado pioneiro na vitivinicultura brasileira e de ser um grande envasador, a produção de vinhos a partir de uvas paulistas é relativamente pequena (VERDI e OTANI, 2016).

Atualmente a vitivinicultura nacional constitui-se em uma atividade consolidada, com área de plantio em torno de 84 mil hectares e produção estimada em 984.244 toneladas de uva (MELLO, 2017). A atividade vitivinícola desempenha um forte papel sócio econômico nos principais estados produtores: Rio Grande do Sul, São Paulo, Paraná, Pernambuco, Santa Catarina, Bahia e Minas Gerais.

Segundo dados do IBRAVIN (2016), a produção de uvas no território nacional atingiu cerca de 1.492 .138 toneladas em 2015 , somados os volumes dos principais estados produtores (Tabela 1). No ano de 2016 houve um decréscimo de aproximadamente $30 \%$ na produção nacional devido principalmente a intempéries climáticas ocorridas no Rio Grande do Sul.

Tabela 1: Produção nacional de uva nos principais estados produtores brasileiros nos anos de 2013 à 2016, em toneladas.

\begin{tabular}{lllll}
\hline Estado & $\mathbf{2 0 1 3}$ & $\mathbf{2 0 1 4}$ & $\mathbf{2 0 1 5}$ & $\mathbf{2 0 1 6}$ \\
\hline RS & 808.267 & 812.537 & 876.286 & 415.739 \\
PE & 228.727 & 236.767 & 237.367 & 237.367 \\
SP & $\mathbf{1 7 2 . 8 6 8}$ & $\mathbf{1 4 6 . 7 9 0}$ & $\mathbf{1 4 2 . 0 6 3}$ & $\mathbf{1 4 2 . 9 6 7}$ \\
PR & 79.052 & 80.910 & 64.806 & 42.750 \\
BA & 52.808 & 77.504 & 77.401 & 57.240 \\
SC & 57.985 & 66.106 & 69.118 & 37.344 \\
Subtotal & 1.399 .707 & 1.420 .614 & 1.467 .041 & 933.407 \\
\hline Total Br. & $\mathbf{1 . 4 1 7 . 6 7 7}$ & $\mathbf{1 . 4 3 6 . 0 7 4}$ & $\mathbf{1 . 4 9 2 . 1 3 8}$ & $\mathbf{9 5 8 . 6 7 6}$ \\
\hline
\end{tabular}

Fonte: VERDI e OTANI (2016)

A vitivinicultura mineira está representada tradicionalmente em dois polos vitícolas: um ao norte de Minas Gerais (Pirapora), bastante tecnificado e destinado à produção de uvas para mesa durante todo o ano, e outro ao Sul do estado (região de 
Caldas e Andradas), constituído basicamente por pequenos vinhedos e vinícolas de médio e pequeno porte.

São Paulo apresenta regiões já consolidadas na produção de uva, como Campinas, Itapetininga, Jales e Sorocaba, que formam quatro zonas produtoras importantes e tradicionais do estado, responsáveis por 93\% de sua produção total (VERDI e OTANI, 2016).

A criação do Circuito das Frutas na região de Campinas e do Roteiro do Vinho em São Roque - esta última tendo movimentado, em 2009, aproximadamente 70 mil turistas durante os finais de semana (VERDI et al., 2011) - trouxe à tona o problema da pouca quantidade de vinhos genuinamente oriundos dessas regiões, as quais não possuem muitos rótulos finos, e sim o tradicional vinho elaborado com uva Vitis labrusca.

A produção de vinhos finos, elaborados com variedades europeias, ainda é incipiente no Estado, mas constitui uma atividade econômica promissora para o agronegócio paulista. Estima-se que em torno de 30 milhões de brasileiros são consumidores regulares de vinhos e 800 mil são aficionados, cuja preferência são os vinhos tintos, seguidos pelos espumantes. Os brancos, apesar de ainda venderem pouco, possuem um mercado crescente, já os rosados têm um consumo bem restrito (COPELLO, 2015).

Em pesquisa conduzida pela Agência Paulista de Tecnologia dos Agronegócios (APTA), juntamente com a Câmara Setorial de Uva e Vinho do Estado de São Paulo, ligada a Secretaria de Agricultura e Abastecimento do Estado de São Paulo - SAA/SP foram realizados levantamentos durante os anos de 2015 a 2016. Constatou-se uma mudança de paradigma na vitivinicultura paulista com o surgimento de novos empreendedores, sem tradição na área agrícola, com altos investimentos em 
tecnologia e mão de obra qualificada para a elaboração de vinhos finos de qualidade (Figura 1).

Figura 1: Regiões produtoras do estado de São Paulo, destacando regiões tradicionais e regiões emergentes.

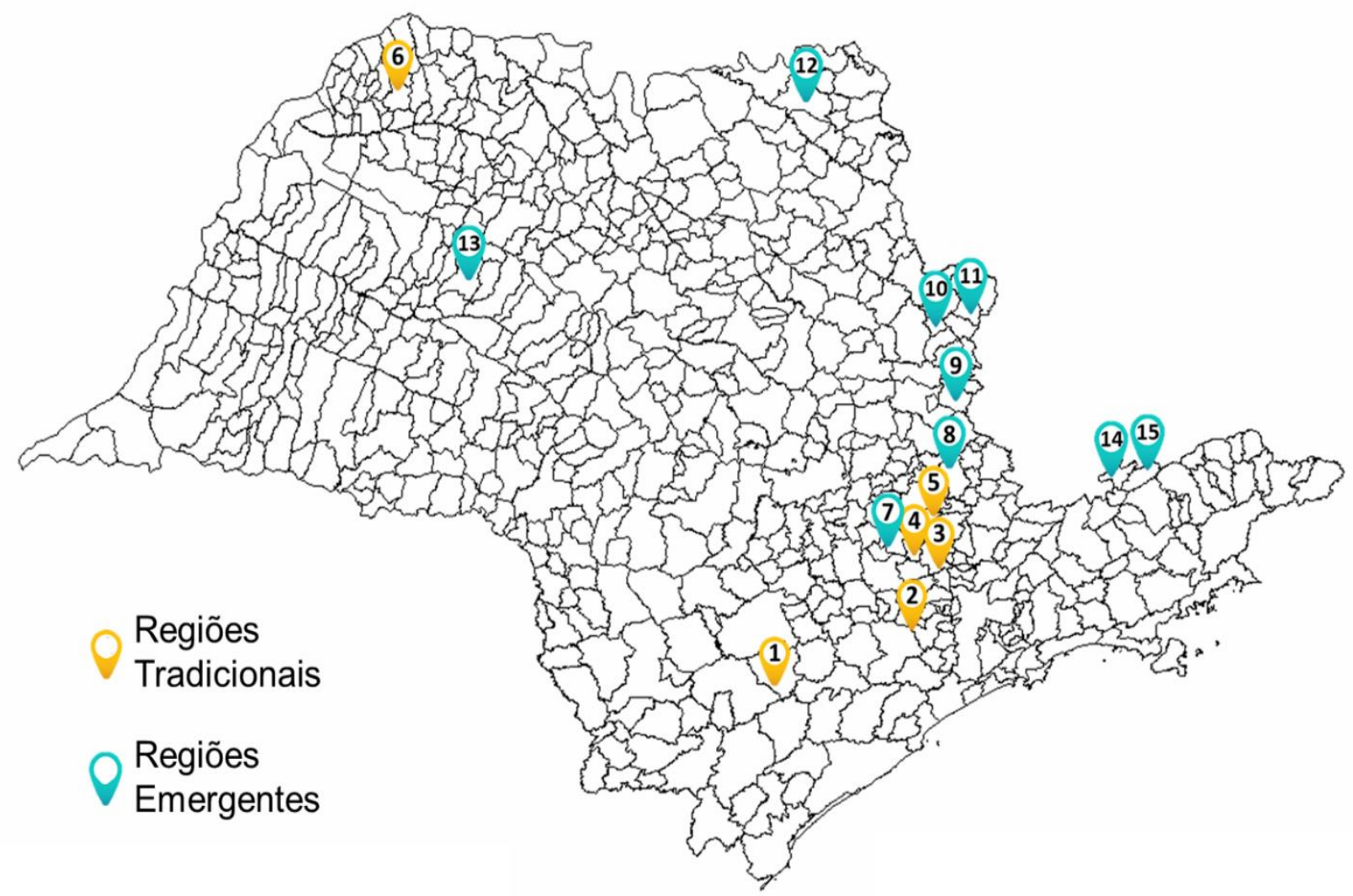

(1) São Miguel Arcanjo; (2) São Roque; (3) Jundiaí; (4) Itupeva; (5) Louveira; (6) Jales; (7) Indaiatuba; (8) Amparo; (9) Espirito Santo do Pinhal; (10) Itobí; (11) Divinolândia; (12) Ituverava; (13) Penápolis; (14) São Bento do Sapucaí; (15) Campos do Jordão.

Fonte: AMARAL, L. B (2020)

Como as regiões produtoras são bastante dispersas, com variações de clima e solo, torna-se agora necessário caracterizar os diferentes componentes da produção vitícola, tais como clima, solo, expressão fisiológica, vegetativa e produtiva das plantas, assim como as características analítico-sensoriais dos vinhos. O conhecimento dessas variáveis servirá de subsídios para traçar o perfil qualitativo do 
vinho, como forma de valorizar sua tipicidade e contribuir para futura indicação de origem dos vinhos de inverno do Sudeste brasileiro

Para se elaborar um bom vinho, é indispensável compreender as características das variedades de uvas e como elas podem se expressar harmonicamente nos vinhos. Quando uma variedade específica se encontra em regiões geográficas diferentes e é vinificada usando as mesmas técnicas, o vinho produzido possuirá certas qualidades inerentes à personalidade da região (BELANCIC e AGOSTIN, 2000).

Compreender como uma variedade em particular pode contribuir no processo de vinificação é essencial para a elaboração de vinhos de alta qualidade. $O$ conhecimento mais profundo das diversas estruturas presentes na uva e os mecanismos de sua evolução durante a vinificação são base indispensável na avaliação do papel da variedade em enologia e no desenvolvimento de processos tecnológicos adaptados ao potencial da matéria prima e ao tipo de produto desejado. (FLANZY, 2000).

A partir destas informações, é de se esperar que o Sudeste alcance um novo patamar em sua vitivinicultura, ingressando no cenário nacional da produção de vinhos finos de qualidade.

\subsection{Ciclo extemporâneo de inverno}

Assim como ocorre em boa parte das regiões vitícolas do Sul, a fase de maturação e colheita da uva no Sudeste coincide com o período de elevada intensidade pluviométrica responsável por efeitos negativos sobre a qualidade e sanidade das uvas (SILVA, 1998). A ocorrência de chuvas durante a fase de desenvolvimento das bagas, além de favorecer a incidência de doenças fúngicas, 
provoca atraso na maturação das uvas, redução da cor, elevação do pH e acidez do mosto com consequente redução do potencial qualitativo dos vinhos (JACKSON e LOMBARD, 1993).

Estudo desenvolvido por Conceição e Tonietto (2005) indicou condições climáticas favoráveis para a elaboração de vinhos finos na região sul de Minas Gerais no período de outono-inverno. Amorin et al. (2005) verificaram que é viável a alteração do ciclo da videira Syrah para que a maturação das bagas ocorra nos meses mais secos do ano pela técnica da dupla poda, prática corrente no manejo de variedades de mesa em regiões tropicais.

Figura 2: Ciclo extemporâneo de produção de uva.

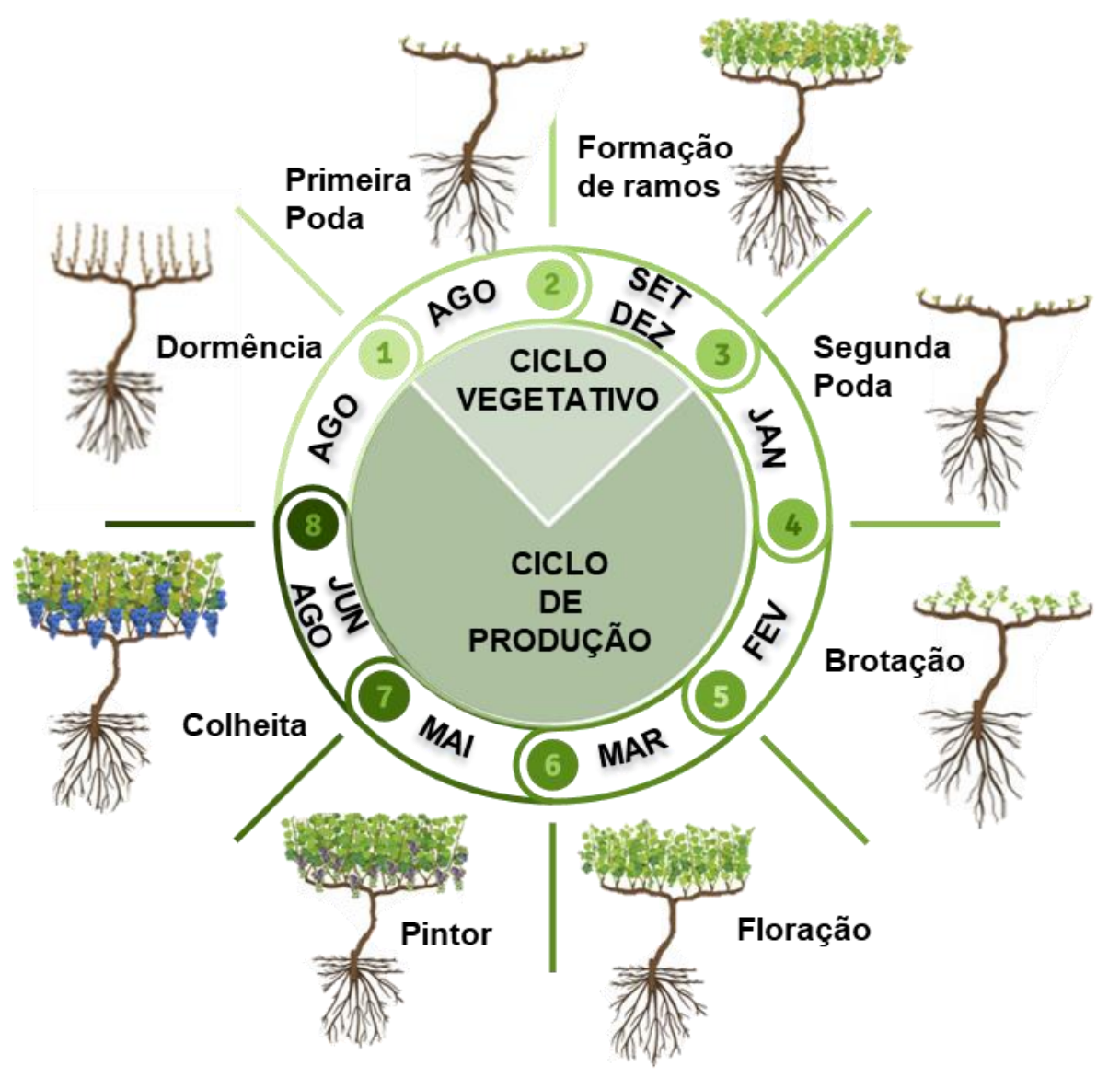

Fonte: Amaral L.B (2020) 
A dupla poda consiste em podar a planta duas vezes no mesmo ciclo, alterando o período convencional da colheita. A primeira poda ocorre normalmente em agosto e tem como objetivo formar ramos. Os cachos provenientes dessa poda são descartados. A segunda poda é realizada entre dezembro e fevereiro (verão), após a lignificação dos ramos. Os cachos provenientes da segunda poda são mantidos. Assim, a colheita é feita de junho a agosto, durante o outono/inverno, quando a precipitação é menor (Figura 2).

Através do manejo de dupla-poda, a baga tem um aumento na qualidade, pois se permite manter o cacho na planta até atingir maturação fenólica e maior concentração de açúcar, consequentemente obtém-se um aumento na qualidade (DIAS et al, 2017) dos vinhos (MOTA et al, 2011). As variedades que mais se adaptaram ao novo manejo até o momento foram Sauvignon Blanc, Chardonnay, Viognier, Cabernet Sauvignon, Cabernet Franc, Malbec, Pinot Noir e principalmente a Syrah (VERDI e OTANI, 2016).

\subsection{Cultivar Syrah}

A variedade teve sua origem no cruzamento entre "Mondeuse Blanche" (variedade branca originária do Departamento de Savoie) e "Dureza" (variedade tinta originária do Departamento de Ardeche) (ENTAV, 1995). Possui cacho pequeno a médio e bagas pequenas (GIOVANNINI, 2014).

Trata-se de uma cultivar muito vigorosa, com produção média de 6.000 a 7.000 $\mathrm{Kg}_{\mathrm{ha}}{ }^{-1}$. É uma variedade muito rica em polifenóis, especialmente antocianinas, produzindo vinhos escuros e bastante aromáticos, com aromas de flores: violetas e cravos, bem como framboesa, amora e groselha (TOGORES, 2011). 
Foi disseminada para outras regiões ao redor do mundo por volta de 1970 (ORLANDO, 2008). No Brasil, a variedade foi introduzida na região Sudeste em 1996 pela Empresa de Pesquisa Agropecuária de Minas Gerais (EPAMIG), mostrando boa adaptabilidade à inversão de ciclo (DAL'OSTO, 2012) e vem apresentando bons resultados de maturação e vinhos de qualidade superior no Sudeste e Nordeste do país (CAMARGO, 2009).

Para Carbonneau (2010), a variedade Syrah mostra excelentes resultados no Sudeste brasileiro. Os vinhos são caracterizados por um grande frescor e uma acidez excelente. "O mundo vitícola certamente em breve falará dos "terroirs" de altitude do Sudeste e de seus vinhos de inverno, paradoxo de frescor em um mundo tropical" segundo Cabornneau, (2010).

\subsection{Elaboração de vinho tinto}

Pela definição legal brasileira, vinho é a bebida obtida pela fermentação alcoólica do mosto simples de uvas sãs, frescas e maduras (LEI № 7.678 DE 08/11/88, MAPA). A elaboração de vinhos tintos consiste em uma somatória de técnicas e procedimentos que podem ser divididos segundo Giovannini e Manfroi (2013), em tratamento mecânico, também conhecido como desengace, fermentação alcoólica e maceração, descuba, fermentação malolática e envase, essas etapas consistem no sistema clássico de vinificação.

Figura 4: Processo de elaboração de vinho tinto pelo método tradicional

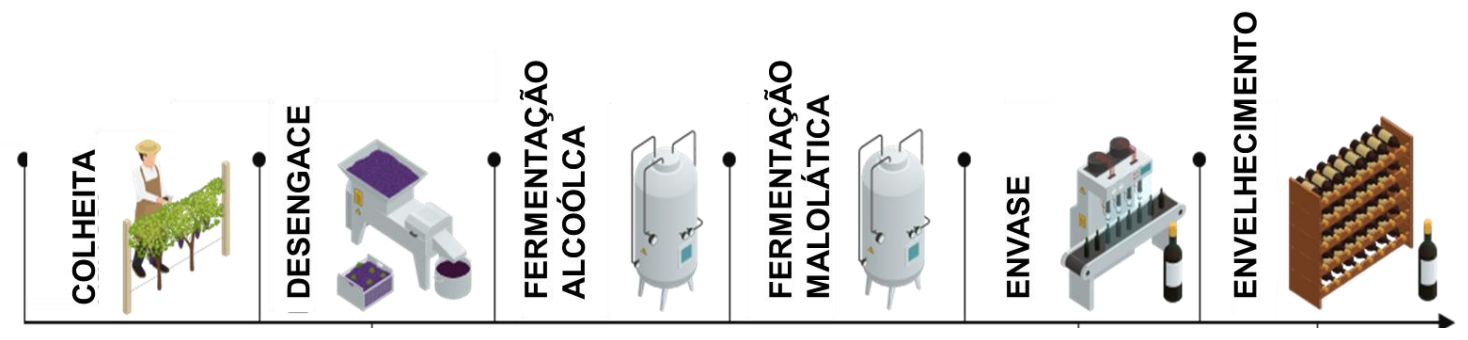

Fonte: Amaral, L. B. (2020) 
O processo de elaboração do vinho começa dentro do vinhedo, com o início da poda. Ao longo do ciclo são feitas várias intervenções de manejo do vinhedo como, desbrota, desponte, raleio de cachos, desfolha e aplicação de defensivos químicos (GIOVANNINI, 2014). A partir do pintor, inicia-se o acompanhamento da maturação das bagas com análises de $\mathrm{pH}$, acidez total, densidade e sólidos solúveis totais. Quando a uva atinge a maturação desejada, é levada até a vinícola, onde é pesada e o processo de "desengace" é iniciado. Esse processo consiste na separação entre a baga e a ráquis (engaço), podendo ser manual ou por máquinas (desengaçadeira), objetivando diminuir os aromas herbáceos e amargores causados pelos engaços (AMORIN et al, 2006).

Após os processos de desengace, é adicionado dióxido de enxofre ou anidrido sulfuroso $\left(\mathrm{SO}_{2}\right)$, para proteger o mosto contra a ação do oxigênio e da contaminação microbiana. Ribéreau-Gayon et al (2004), comentam que a utilização deste insumo possui a finalidade de proteção contra as oxidações (antioxidante), inibições do desenvolvimento de micro-organismos (antisséptico), inibição de enzimas oxidativas (antioxidásico) e proteção dos aromas do vinho. Em seguida, após uma a duas horas da adição do $\mathrm{SO}_{2}$, utilizam-se enzimas pectolíticas, favorecendo a extração dos polifenóis e a liberação do mosto, aumentando assim seu rendimento e atuando também nos processos de filtração e clarificação (MARIN, 2003).

Posteriormente, as uvas são transportadas até o tanque de fermentação, onde leveduras secas ativas selecionadas (na maior parte dos casos são Saccharomyces cerevisiae) podem ser adicionadas dando início à fermentação alcoólica. O processo de fermentação alcoólica objetiva a transformação dos açúcares em álcool, tendo como subproduto gás carbônico (LIU et al, 2018). Juntamente ao processo de fermentação alcoólica ocorre a maceração, etapa que consiste no período em que as 
cascas e sementes ficam em contato com o mosto, buscando extrair principalmente compostos fenólicos presentes nas cascas, como as antocianinas responsáveis pela cor e os taninos, fortes antioxidantes, responsáveis pela estrutura dos vinhos e pela sensação de adstringência na boca (TOGORES, 2011). Durante esses processos são realizadas análises de temperatura e densidade para acompanhar o andamento da fermentação.

Ao término da fermentação é realizado a "descuba", que consiste na separação da parte líquida (vinho) da parte sólida (bagaço). Retira-se o líquido que é levado (trasfegado) até outro tanque, a parte sólida restante pode ser prensada para maior aproveitamento do vinho ou não; essa decisão depende do tipo de vinho que se deseja ter (AMORIN et al, 2006). O vinho prensado apresenta qualidade inferior devido ao seu maior amargor e maior adstringência. Sendo assim, utiliza-se apenas o vinho gota (ou seja, vinho que não foi prensado) quando o produto final almejado tem maior valor agregado (GIOVANNINI E MANFROI, 2013).

Em seguida, ocorre a fermentação malolática, que consiste na transformação do ácido málico, proveniente da uva, em lático por ação das bactérias láticas. Este processo pode ocorrer de maneira natural, com bactérias presentes no mosto ou com adição de bactérias selecionadas. Essa segunda fermentação também é utilizada para estabilizar o vinho microbiologicamente (AWRI, 2016).

Realizada a segunda fermentação, o vinho é trasfegado para outro tanque, com o intuito de eliminar a borra decantada. Em seguida, é realizado o processo de estabilização tartárica, que objetiva insolubilizar sais de bitartarato de potássio. $\mathrm{Na}$ sequência o vinho é trasfegado para outro tanque para separar os sais decantados, com o auxílio do frio. A estabilização tartárica evita o aparecimento de cristais dentro da garrafa. 
Ao término do processo, o vinho passa por análises para determinação de teor alcoólico, açúcares residuais, acidez total, pH, acidez volátil, extrato seco reduzido e dióxido de enxofre livre e total. Então, o vinho é levado para a linha de engarrafamento, onde são envasados e embalados.

\subsection{Compostos Voláteis}

O vinho é uma bebida alcoólica composta por várias substâncias químicas, incluindo ácidos orgânicos, compostos fenólicos e compostos de aromas, todos eles desempenhando papel importante na qualidade final do produto (SENER, 2018). A percepção aromática no vinho é um dos fatores mais importantes para determinar sua complexidade e qualidade (VILANOVA et al., 2007), além de ser um parâmetro de identidade regional e de aceitação do consumidor (SELLI et al, 2004). Vários fatores podem influenciar os compostos de aroma, como solo e clima, cultivar, nível de maturação, levedura, processos de produção e envelhecimento (JIANG, 2010), afetando as características do vinho individualmente e através das interações uns com os outros.

Os compostos voláteis podem ser classificados segundo Belancic e Agosin (2002) em 4 grupos:

- Compostos "varietais": são os aromas resultantes do metabolismo da própria variedade, influenciados somente por fatores externos, como solo e o clima.

- Compostos pré-fermentativos: são obtidos a partir dos fenômenos que sucedem a obtenção do mosto, como oxidação dos compostos bioquímicos e hidrólise de alguns componentes. 
-Compostos fermentativos: são obtidos a partir das fermentações alcoólica e malolática durante os processos de elaboração do vinho. Os mais abundantes são os álcoois, ácidos, ésteres, compostos carbonilados e sulfurados.

-Compostos pós-fermentativos: são aqueles formados pela conservação do vinho e envelhecimento, em garrafas ou em barricas, através de reações químicas e enzimáticas.

Os compostos voláteis encontrados na uva são metabólitos secundários formados, como nas maiorias das plantas, a partir de compostos primários: carboidratos, ácidos graxos e aminoácidos (AHMED et al., 2017). Esses compostos são sintetizados e acumulados ao longo da maturação do fruto. Durante os processos de elaboração do vinho, esses precursores são substratos para a síntese de novos compostos voláteis, que contribuem com a originalidade e identidade dos vinhos (AGOSIN, 2013).

Figura 5: Principais precursores e vias de formação de compostos voláteis

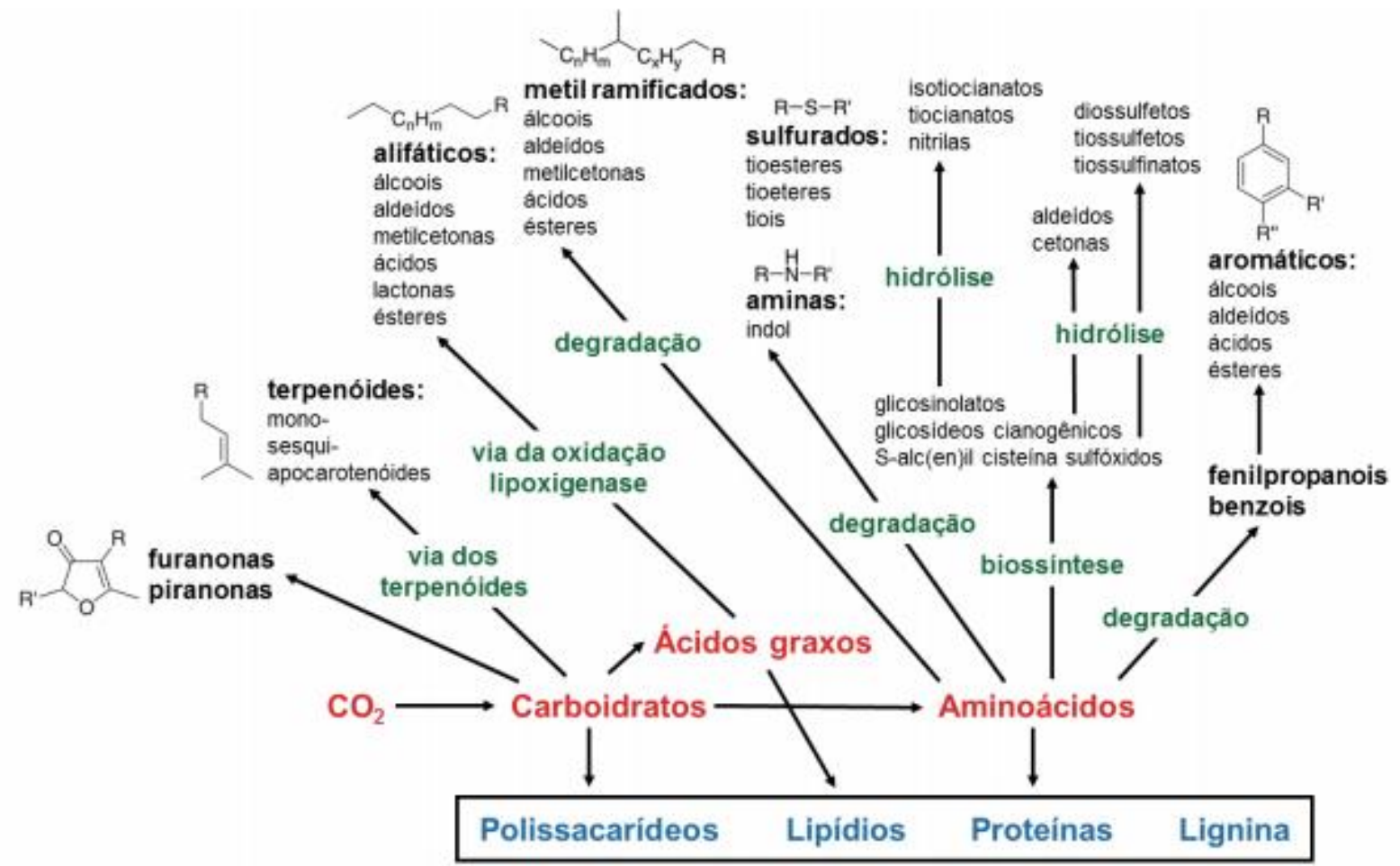

Fonte: Adaptado de Schwab et al., 2008. 
De modo geral, pela via dos carboidratos, são formados principalmente terpenos que estão presentes na uva na forma livre ou glicosilada (PÉREZ e SANZ, 2008). A $\beta$-oxidação de ácidos graxos é o principal processo biossintético que fornece álcoois e acil-coenzima A (acil-CoAs) que são utilizadas pelas álcool aciltransferases (AAT) para formação de ésteres (PALIYATH et al.,2008). Os aminoácidos e seus substratos também estão envolvidos na biossíntese de aromas na fruta, esse metabolismo é responsável pela produção de um grande número de compostos, incluindo álcoois, carbonilas e ácidos (SCHWABET et al., 2008).

A variedade Syrah possui muitos compostos voláteis, é considerada uma variedade aromática e apresenta quantidades de terpenos e ésteres em torno de $1 \mathrm{a}$ $30 \mathrm{mg} \cdot \mathrm{L}^{-1}$. Estes compostos podem ser encontrados em diversas formas, como aldeídos, álcoois, hidrocarbonetos e outros (TOGORES, 2011). A variedade é internacionalmente conhecida por algumas características aromáticas como "picante", aroma que se dá principalmente pela rotundona, traços de "fruta madura" e flores, devido a ésteres e aroma de evolução, como identificado recentemente por algumas moléculas como $\beta$-damascenone, um norisoprenóides C-13 (MAYR et al, 2014), 


\section{2- OBJETIVO}

Este trabalho tem como objetivo traçar o perfil aromático e químico dos vinhos elaborados com variedade Syrah, proveniente de duas regiões distintas do estado de São Paulo, uma quente de baixa altitude (Indaiatuba) e outra fria de alta altitude (São Bento do Sapucaí). O intuito é avaliar se somente a variável local é capaz de gerar diferença entre os produtos obtidos. 


\section{3- MATERIAIS E MÉTODOS}

\section{1 - Matéria prima e condições edafoclimáticas}

Para este experimento foram avaliados dois vinhedos já em produção da cultivar Vitis vinifera L. Syrah (clone 174 ENTAV - INRA® sobre porta-enxerto 1103P - clone 768 ENTAV - INRA®) localizados no estado de São Paulo nas safras 2017 e 2018.

São Bento do Sapucaí (SB) está localizada a uma altitude de 1200m, apresenta clima subtropical de altitude, com inverno seco e verão ameno (CWB - Koeppen), solo argiloso, índices pluviométricos acima de $1700 \mathrm{~mm}$ por ano e temperatura média de 15,1ํㅡ (CIIAGRO). Indaiatuba (IN), com altitude de 575m, clima subtropical de inverno seco (CWA - Koeppen), solo arenoso, índices pluviométricos acima de $1200 \mathrm{~mm}$ por ano e temperaturas médias de $21^{\circ} \mathrm{C}$ (ClIAGRO). Ambos os vinhedos possuem exposição norte-leste, com plantas conduzidas em cordão duplo esporonado no sistema espaldeira com espaçamento de $3 \mathrm{~m}$ entre filas e $1 \mathrm{~m}$ entre plantas. A $2^{\mathrm{a}}$ poda é realizada em esporões com duas gemas em janeiro para colheita em julho (colheita de inverno). As podas de São Bento do Sapucaí foram realizadas nos dias 11/02/2017 e 16/02/2018. Enquanto as podas de Indaiatuba foram realizadas em 10/02/2017 e 08/02/2018.

Figura 6: Regiões de São Bento do Sapucaí (5A) e Indaiatuba (5B)

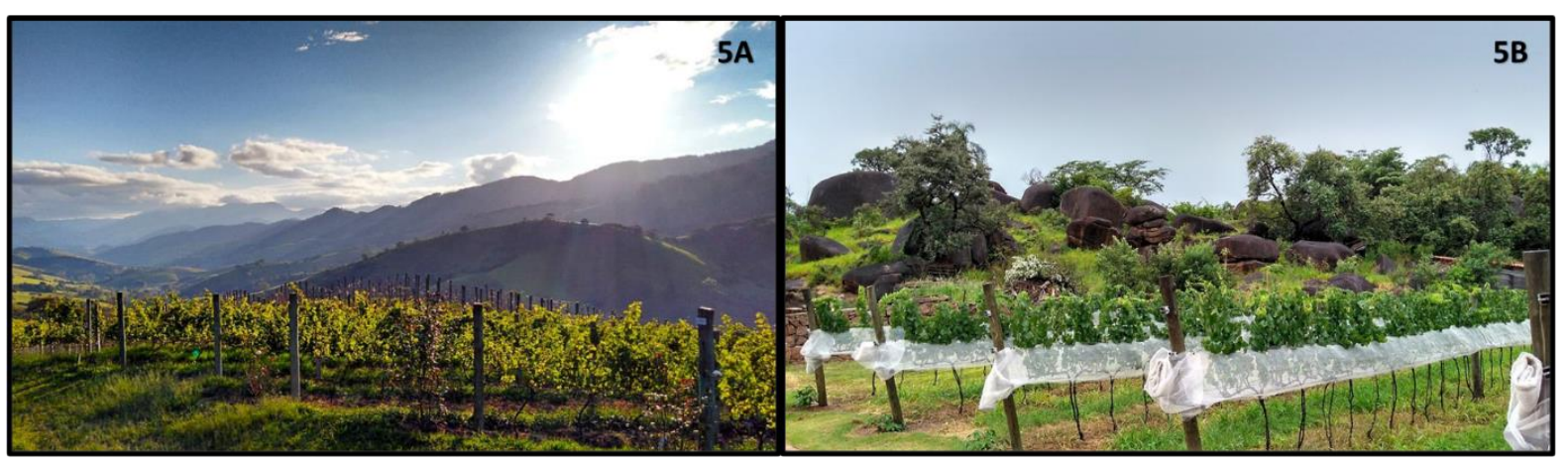

Fonte: AMARAL, L. B. (2020). 
Os dados dos gráficos abaixo foram coletados pelo INMET- Instituto Nacional de Meteorologia e mostram os registros de temperatura e pluviosidade durante a condução do experimento nas safras de 2017 e 2018 de ambas as regiões.

Gráfico 1: Índice de temperatura $\left({ }^{\circ} \mathrm{C}\right)$ de São Bento do Sapucaí e Indaiatuba nas safras de 2017 e 2018.

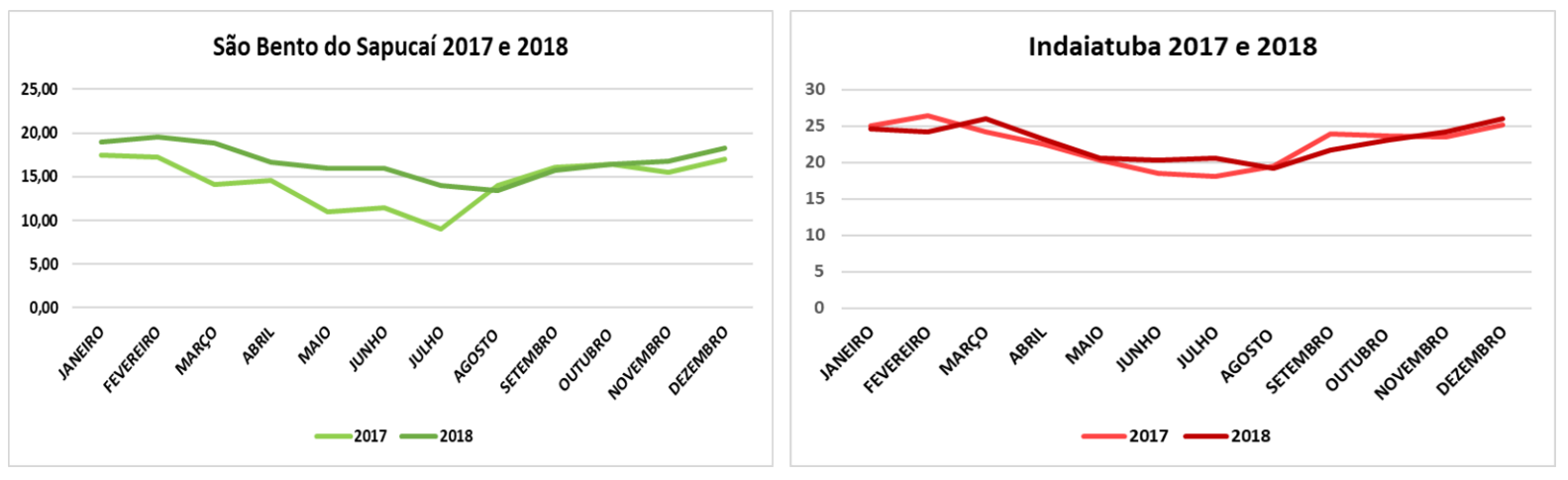

Gráfico 2: Índice pluviométrico $(\mathrm{mm})$ de São Bento do Sapucaí e Indaiatuba nas safras de 2017 e 2018.

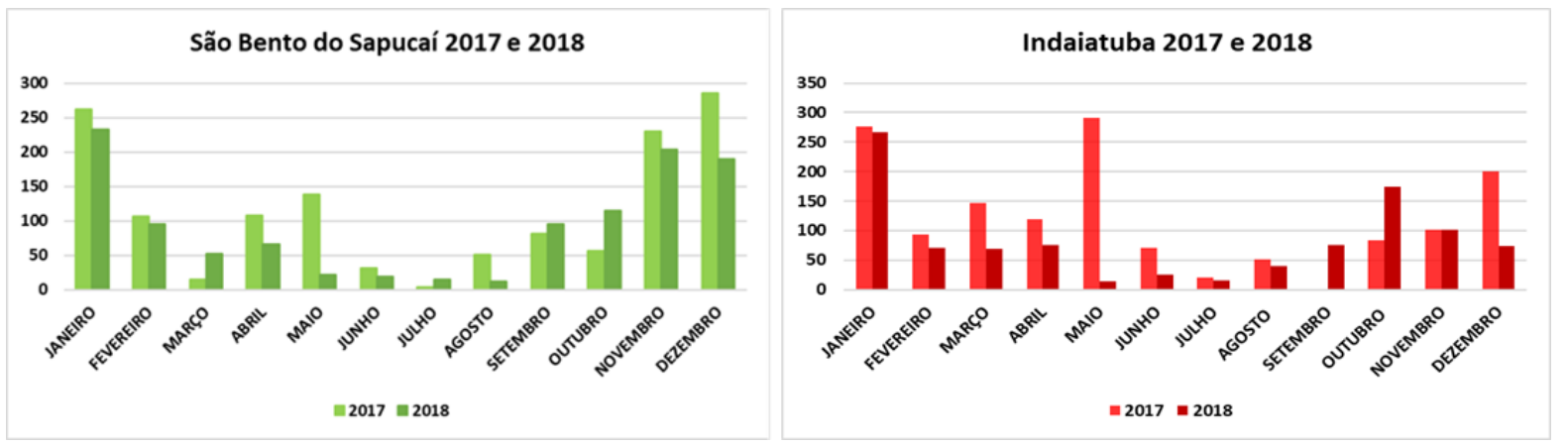

\section{2 - Acompanhamento da maturação e Colheita}

O acompanhamento da maturação foi realizado através de análises do conteúdo de sólidos solúveis totais ( ${ }^{\circ B}$ rix) em refratômetro digital portátil ATAGO modelo Pal 1, acidez total por titulação com $\mathrm{NaOH} 0,1 \mathrm{~N}$ utilizando fenolftaleína como indicador, $\mathrm{pH}$ em pHmetro digital Micronal modelo B 474. A colheita das safras de 2017 e 2018 foram realizadas levando em conta previsões meteorológicas e o aval dos produtores. Durante a colheita foram escolhidas 30 plantas aleatoriamente para a coleta dos cachos. Após a colheita, as uvas foram encaminhadas ao Laboratório de Enologia do Instituto Federal de Educação, Ciência e Tecnologia de São Paulo 
(IFSP), localizado em São Roque (SP), para elaboração do vinho. O transporte foi realizado à noite, sem exposição ao calor para evitar oxidações e manter a qualidade.

Figura 7: Variedade Syrah sob ciclo de inverno em São Bento do Sapucaí (6A) e Indaiatuba (6B).
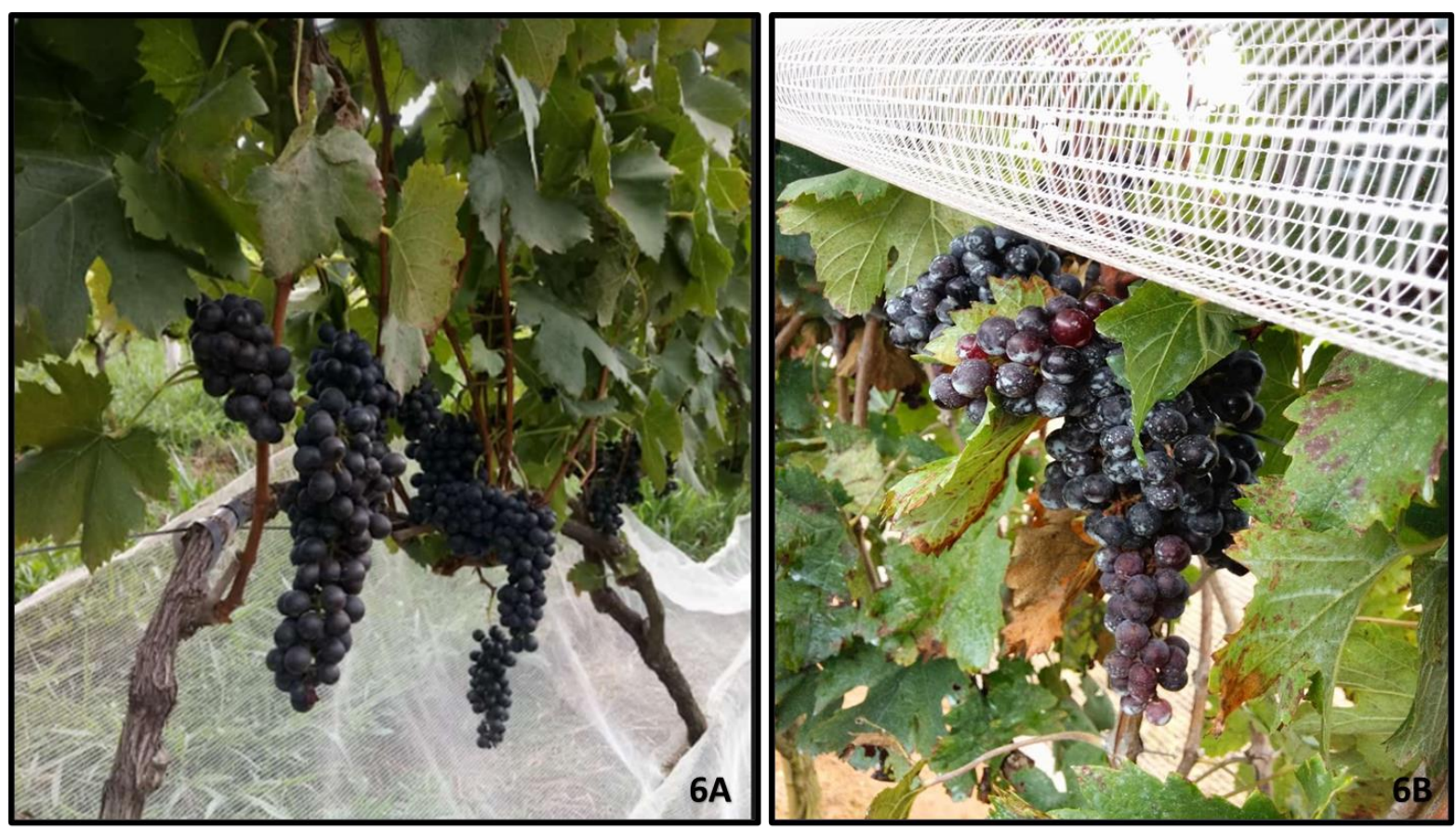

Fonte: Amaral, L. B. (2020).

\subsection{Análise agronômica}

Separou-se aleatoriamente vinte cachos de cada colheita para aferição de peso e comprimento (entre bagas da extremidade superior e inferior do cacho). Também foram separadas 300 bagas para medição do diâmetro e peso. Esses procedimentos foram realizados para as duas regiões durante as safras de 2017 e 2018.

\subsection{Microvinificação}

As uvas das duas regiões em ambas as safras foram vinificadas no IFSP Campus São Roque. Os cachos ficaram armazenados em câmara fria a uma temperatura de $5^{\circ} \mathrm{C}$ após o recebimento para reduzir o calor do campo e evitar oxidações até a manhã do dia seguinte. Em seguida, as bagas foram separadas 
manualmente das ráquis ("desengace") e prensadas com as mãos com força suficiente para que ocorresse somente o rompimento da película e formação do mosto. Foi acrescentado neste momento anidrido Sulfuroso $\left(\mathrm{SO}_{2}\right)$ na forma de sal de metabiSulfito de potássio $\left(\mathrm{K}_{2} \mathrm{SO}_{5}\right)$ como agente antioxidante e antimicrobiano na dosagem de $80 \mathrm{mg} \cdot \mathrm{L}^{-1}$. Após uma hora da adição do $\mathrm{SO}_{2}$ foi adicionada enzima pectolítica (Colorpect) na concentração de $2 \mathrm{~g} \cdot \mathrm{HL}^{-1}$ para quebra da pectina da uva e obtenção do mosto.

Figura 7: Processo de fermentação alcoólica em recipientes de vidro de 25 litros com variedades Syrah das regiões de São Bento do Sapucaí (7A) e Indaiatuba (7B).
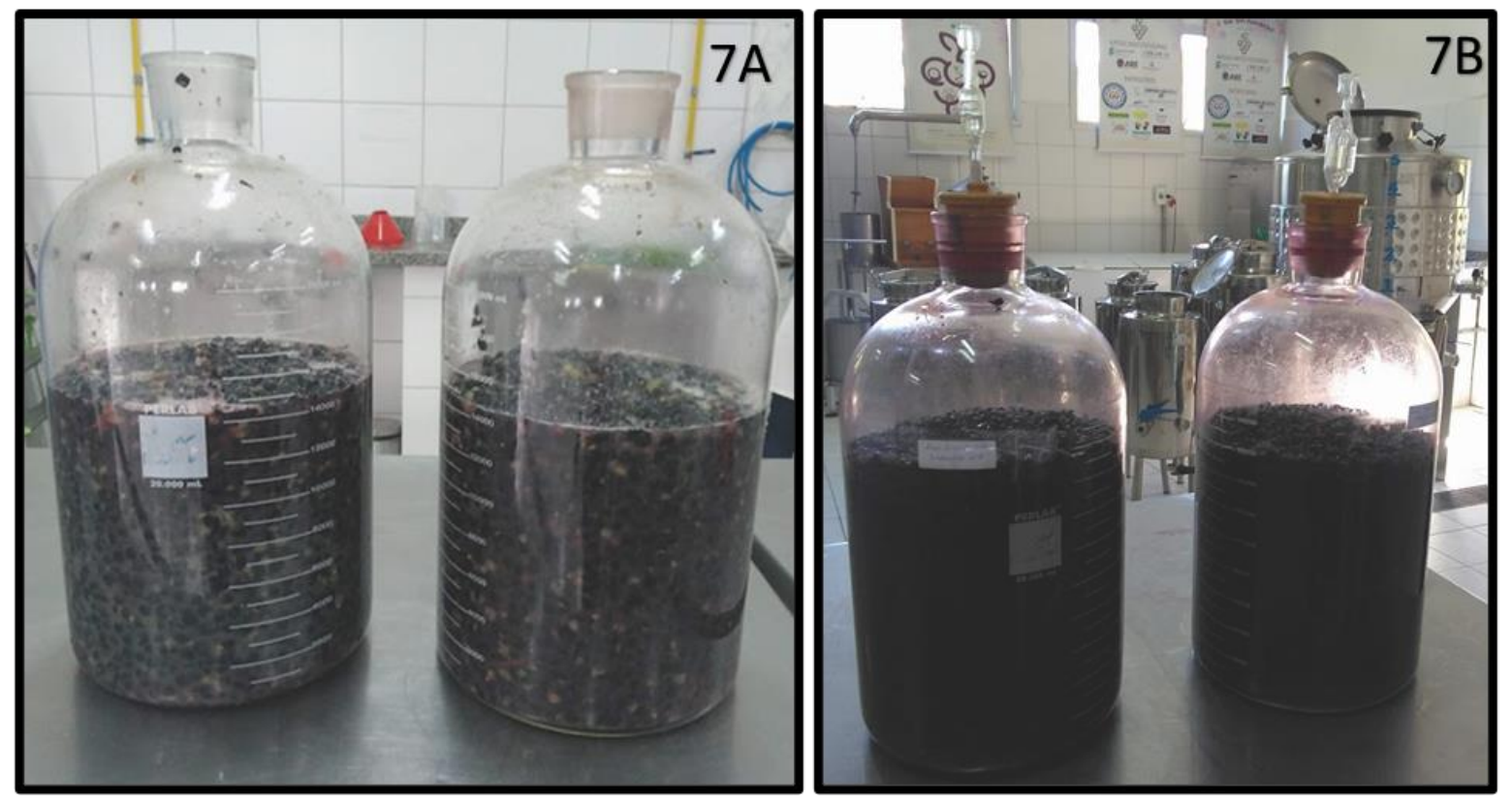

Fonte: AMARAL, L. B. (2020)

Após adição da enzima, foram adicionadas leveduras selecionadas do gênero Saccharomyces cerevisiae, da variedade Maurivin Awri1503, escolhida por ser própria para vinhos da variedade Syrah, na dosagem de $25 \mathrm{~g} \cdot \mathrm{HL}^{-1}$, para realização da fermentação alcoólica em temperatura controlada de $20^{\circ} \mathrm{C}$. Durante o periodo de fermentação foram realizadas diariamente análises de densidade e temperatura até densidade constante abaixo de 1.000, como mostra o anexo 1 . Ao atingir esta densidade, o vinho foi trasfegado para novos Pirex de 25 litros. A fermentação 
malolática ocorreu de forma expontânea e foi acompanhada pela determinação de ácido málico por cromatografia de papel.

Finalizada a fermentação malolática, os vinhos foram trasfegados e corrigiu-se os valores de $\mathrm{SO}_{2}$ livre para $35 \mathrm{mg} \cdot \mathrm{L}^{-1}$. Depois, os vinhos foram colocados na câmara fria a $-5^{\circ} \mathrm{C}$ para estabilização tartárica por quinze dias, e posteriormente foram trasfegados e envasados em garrafas de $750 \mathrm{ml}$. As garrafas ficaram em ambiente protegido da luz até completarem seis meses e doze meses de envase.

Durante o processo de elaboração do vinho foram retiradas amostras das principais etapas de elaboração (Mosto, Fermentação Alcoólica, Fermentação Malolática, Envase, 6 Meses e 12 meses). As amostras ficaram congeladas a $-80^{\circ} \mathrm{C}$ em ultrafreezer até realização das analises.

\subsection{Análise de ácidos orgânicos}

Os ácidos tartárico e málico foram determinados na fração ácido obtida após passagem do vinho em uma resina de troca aniônica Bio-Rex 5 (Bio Rad Labs) (McCord et al., 1984). Uma alíquota de $20 \mu \mathrm{L}$ foi injetada em cromatógrafo líquido Hewlett-Packard, modelo 1100, equipado com coluna SupelcoGel C-610H (Supelco, $30 \mathrm{~cm} \times 7,8 \mathrm{~mm}$ ) ajustada a uma temperatura de $15^{\circ} \mathrm{C}$, e detector arranjo de diodos (DAD) a $245 \mathrm{~nm}$. Foi realizada uma corrida isocrática a um fluxo de $0,5 \mathrm{~mL} \mathrm{~min}-1$ utilizando solução de ácido fosfórico a $0,5 \%$ como fase móvel. A identificação e quantificação dos cromatogramas foram baseadas em solução padrão dos ácidos tartárico e málico.

\subsection{Análise de voláteis}

Utilizou-se a técnica de microextração em fase sólida (SPME) com fibra 50/30 $\mu \mathrm{m}$ DVB/CarboxenTM/PDMS StableFlexTM(Supelco®). A metodologia para a extração de aroma foi realizada de acordo com SUN et al., (2011), adaptada para a 
variedade Syrah.Foram pipetados $10 \mathrm{~mL}$ da amostra de vinho em um frasco de cerca de $40 \mathrm{~mL}$ de capacidade, e adicionado $07 \mu \mathrm{L}$ de Methyl Heptanoato (Merck®) como padrão interno de quantificação relativa. O frasco foi fechado com tampa plástica, vedado com parafilm, e aquecido na chapa térmica a $40{ }^{\circ} \mathrm{C}$ por 20 minutos para 0 equilíbrio dos compostos voláteis com a fase aérea do frasco. Em seguida, a fibra de SPME foi introduzida no frasco e exposta ao ar do seu interior por 30 minutos a 40 ${ }^{\circ} \mathrm{C}$, com agitação constante. Uma vez recolhida a amostra, esta foi dessorvida da fibra pela exposição ao calor do injetor do cromatógrafo $\left(250^{\circ} \mathrm{C}\right)$ por 2 minutos. Foi utilizado o cromatógrafo Agilent modelo 7890, acoplado a um detector seletivo de massas da mesma empresa, modelo 5977. A coluna cromatográfica empregada foi a Supelcowax 10 (30 mts, 0,25 mm de diam. interno, 0,25 $\mu \mathrm{m}$ de espessura do filme). O programa de temperatura utilizado foi: rampa de $35^{\circ} \mathrm{C}$ por 5 minutos, $4.5^{\circ} \mathrm{C}$ por minuto até atingir $170^{\circ} \mathrm{C}$, posteriormente $8^{\circ} \mathrm{C}$ por minuto até atingir $250^{\circ} \mathrm{C}$ e se manteve na temperatura máxima por 5 minutos.

\subsection{Análise de dados voláteis}

Os espectros de massas obtidos foram tratados com o software MassHunter Qualitative Analysis (versão: B.07.00, Agilent Technologies, Inc. 2014) e comparados com os espectros da biblioteca NIST 2014. Foram considerados somente os compostos com um mínimo de similaridade de $70 \%$.

Para a confirmação dos compostos voláteis pelo Índice de Retenção de Kovats, utilizou-se um padrão de n-alcanos saturados (C7 a C30) nas mesmas condições do método de análise, estabelecendo o tempo de retenção dos alcanos. Aplicou-se a fórmula do índice de retenção Kovats modificado, aplicado aos métodos com rampa de temperatura, para obter o índice de retenção observado para cada composto e comparou-se com o índice de retenção Kovats da literatura, obtido através da base 
de dados online (NIST Chemistry Webbook) e de acordo com a polaridade da coluna capilar utilizada.

Os perfis de compostos voláteis foram comparados em relação aos experimentos de cada vinhedo e safras, sendo empregada sobre os perfis globais de voláteis a Análise de Componente Principal (Principal Components Analysis, PCA), técnica de análise dos dados multivariados usado para a redução da dimensionalidade dos dados, mostrar possíveis relações entre os compostos voláteis identificados em cada experimento e visualizar outliers (CAPONE et al., 2013; Cozzolino et al., 2005)

Utilizando o programa MetaboAnalyst 4.0 (www.metaboanalyst.ca) (XIA, SINELNIKOV, et al., 2015), os dados são normalizados pela mediana, tratados na escala logarítmica e escalonados segundo a escala de Pareto. 


\section{4- RESULTADOS E DISCUSSÕES}

\section{1 - Análises agronômicas}

As análises agronômicas mostraram que os valores de diâmetro das bagas, peso das bagas, tamanho dos cachos e peso dos cachos diferem entre as regiões e entre as $\operatorname{safras}(p<0,05)$, como mostra a tabela 2 .

Tabela 2: Análise agronômica das regiões de São Bento do Sapucaí e Indaiatuba, safras 2017 e 2018.

\begin{tabular}{lcccc}
\hline $\begin{array}{l}\text { Região/ } \\
\text { safra }\end{array}$ & $\begin{array}{c}\text { Diâmetro das } \\
\text { Bagas }(\mathbf{m m})\end{array}$ & $\begin{array}{c}\text { Peso das bagas } \\
\mathbf{( g )}\end{array}$ & $\begin{array}{c}\text { Comprimento do } \\
\text { cacho }(\mathbf{c m})\end{array}$ & $\begin{array}{c}\text { Peso do cacho } \\
\text { (g) }\end{array}$ \\
\hline SB2017 & $12,43 \pm 0,95 \mathrm{a}$ & $1,26 \pm 0,17 \mathrm{~b}$ & $13,02 \pm 1,35 \mathrm{a}, \mathrm{b}$ & $101,76 \pm 29,71 \mathrm{~b}$ \\
IN2017 & $11,09 \pm 0,95 \mathrm{C}$ & $1,41 \pm 0,17 \mathrm{a}$ & $10,87 \pm 1,35 \mathrm{~b}$ & $76,26 \pm 29,71 \mathrm{~b}, \mathrm{C}$ \\
SB2018 & $11,76 \pm 0,95 \mathrm{~b}$ & $1,01 \pm 0,17 \mathrm{C}$ & $12,09 \pm 1,35 \mathrm{a}, \mathrm{b}$ & $68,58 \pm 29,71 \mathrm{C}$ \\
IN2018 & $10,21 \pm 0,95 \mathrm{~d}$ & $1,23 \pm 0,17 \mathrm{~b}$ & $14,05 \pm 1,35 \mathrm{a}$ & $134,41 \pm 29,71 \mathrm{a}$ \\
\hline
\end{tabular}

Médias seguidas por letras diferentes na mesma coluna mostram diferenças significativas pelo Teste de Tukey $(p<$ 0,05). SB2017:São Bento do Sapucaí 2017; SB2018:São Bento do Sapucaí 2018; IN2017:Indaiatuba 2017; IN2018: Indaiatuba 2018.

Foram observados diferenças entre os valores médios nos quatro parâmetros, entre todas as amostras, o que é mais provavelmente relacionado aos níveis de maturação entre as safras e regiões. Os valores encontrados para o diâmetro das bagas SB2017, IN2017, SB2018 e IN2018 foram semelhantes aos encontrados por Mota et al, (2007), nas safras de 2007 e 2008 na região da Serra da Mantiqueira - MG; também são semelhantes aos valores encontrados por Favero et al. (2008), em vinhedos localizados ao Sul de Minas Gerais.

O peso das bagas de IN2017, está próximo aos valores encontrados por Mota et al, (2007), de 1,43g e de Pisciotta et al (2013) na África do Sul. Os valores encontrados de SB2017, SB2018 e IN2018 são semelhantes aos encontrados por Vanleeuwen et al (2004) em Bordeaux e por Benz et al (2006) em Napa Valley.

Mota et al, (2007), encontraram valores semelhantes aos de SB2017 e IN2018 para o tamanho dos cachos de Syrah. Enquanto IN2017 e SB2018 foram semelhantes ao valores descritos por Junior et al (2019). O peso dos cachos 
encontados em SB2017 e IN2018 são próximos aos encontrados por Mota et al, (2007), e por Junior et al (2019). Já IN2017 e SB2018 estão abaixo dos valores encontrados na literatura. Essa diferença entre os tamanhos dos cachos pode ser dado por diferenças climaticas e pluviométrica e por tratos culturais diferentes entre os dois vinhedos (BOLETIM 200 IAC, 1998)

Os indices de maturação tecnológica foram quantificados durante a colheita e também durante a obtenção do mosto. O conteúdo de sólidos solúveis totais (SST) em ${ }^{\circ}$ Brix, densidade, acidez total em meq. ${ }^{-1}$ e $\mathrm{pH}$ foram analisados, como mostra a tabela 3. A análise estatística mostra que existe diferença significativa entre as safras e entre as regiões.

Tabela 3: Análise química do mosto das regiões de São Bento do Sapucaí e Indaiatuba, safras 2017 e 2018.

\begin{tabular}{|c|c|c|c|c|}
\hline $\begin{array}{c}\text { Análises quimicas do } \\
\text { mosto }\end{array}$ & SBS 2017 & IN 2017 & SBS 2018 & IN 2018 \\
\hline SST (BRIX) & $21,5 \pm 1,49 \mathrm{C}$ & $20,0 \pm 1,49 \mathrm{~d}$ & $22,5 \pm 1,49 \mathrm{~b}$ & $23,5 \pm 1,49 \mathrm{a}$ \\
\hline Densidade & $1090 \pm 3,42 \mathrm{~b}$ & $1084 \pm 3,42 \mathrm{~d}$ & $1088 \pm 3,42 \mathrm{C}$ & $1092 \pm 3,42 \mathrm{a}$ \\
\hline Acidez total (meq.L-1) & $100 \pm 9,03 \mathrm{~b}$ & $105 \pm 9,03 \mathrm{a}$ & $94 \pm 9,03 \mathrm{C}$ & $84 \pm 9,03 \mathrm{~d}$ \\
\hline pH & $2,90 \pm 0,57 \mathrm{~d}$ & $2,97 \pm 0,57 \mathrm{c}$ & $3,94 \pm 0,57 \mathrm{a}$ & $3,90 \pm 0,57 \mathrm{~b}$ \\
\hline Ácido citrico (ml..-1) & $0,27 \pm 0,06 \mathrm{a}$ & $0,15 \pm 0,06 \mathrm{~b}$ & $0,23 \pm 0,06 \mathrm{ab}$ & $0,15 \pm 0,06 \mathrm{~b}$ \\
\hline Ácido tartárico (ml.L-1) & $9,45 \pm 2,17 \mathrm{a}$ & $6,72 \pm 2,17 \mathrm{ab}$ & $6,21 \pm 2,17 \mathrm{~b}$ & $4,18 \pm 2,17 \mathrm{~b}$ \\
\hline Ácido malácio (ml.L-1) & $6,10 \pm 1,2 \mathrm{a}$ & $4,08 \pm 1,2 \mathrm{~b}$ & $3,24 \pm 1,2 \mathrm{~b}$ & $4,41 \pm 1,2 \mathrm{~b}$ \\
\hline Ácido succínico (ml.L-1) & $1,68 \pm 0,7 \mathrm{ab}$ & $1,56 \pm 0,7 \mathrm{ab}$ & $0,61 \pm 0,7 \mathrm{~b}$ & $2,41 \pm 0,7 \mathrm{a}$ \\
\hline
\end{tabular}

Médias seguidas por letras diferentes na mesma coluna mostram diferenças significativas pelo Teste de Tukey $(p<0,05)$. SB2017:São Bento do Sapucaí 2017; SB2018:São Bento do Sapucaí 2018; IN2017:Indaiatuba 2017; IN2018: Indaiatuba 2018.

Em ambas regiões, a safra de 2018 apresentou caracteristicas mais favoráveis a elaboração do vinho tinto, com maiores teores de sólidos soluveis, densidade e acidez total. Isso pode estar relacionado ao fato de que em ambas as regiões houve menor índice pluviométrico na fase de maturação da uva (junho a agosto). Para SB em 2017, a precipitação foi de $87,3 \mathrm{~mm}$. Já em 2018, foi de 45,8 mm. Da mesma maneira, IN apresentou índice pluviométrico em 2017 de 142,8 mm enquanto em 2018 apresentou 81,6 mm. 
Os valores encontrados de Brix para IN2017 e SB2017 foram semelhantes aos encontrados por Mota et al (2007) no sul de Minas Gerais, Lins et al (2015) em Pretolina e Gris et al (2010) Santa Catarina. Para IN2018 e SB2018 apresentam valores próximos aos encontrados por Ribeiro et al (2018) no Vale do São Francisco. Todas as amostras apresentam níveis de SST adequados para elaboração de vinho fino de qualidade segundo Gris et al (2010), que colocam como faixa de valores de $19 \stackrel{\circ}{\circ} \mathrm{BRIX}$ até $25^{\circ} \mathrm{BRIX}$.

O pH encontrado para SB2017 e IN2017 apresentam valores inferiores aos encontrados na literatura. Esses valores podem estar ligados ao maior índice pluviométrico que ocorreram durante o periodo de desenvolvimento das bagas como mostra o gráfico de indice pluviométrico 1, podendo levar a maior acúmulo de ácidos orgânicos. SB2018 e IN2018 apresentam valores superiores aos encontrados por Mota et al (2007), Gris et al (2010) e Orlando et al (2008). A acidez total condiz com os valores de $\mathrm{pH}$ encontrados.

As análises de ácidos orgânicos, avaliadas pelo teste de Tunkey $(<0,05)$, mostraram que para o ácido citrico existe semelhança entre as amostras SB2017, SB2018 e entre as amostras IN2017, IN2018 e SB2018.

Os valores de ácido tartárico encontrados para IN2017 e IN2018 são semelhantes aos encontrados por Silva et al (2015). O valor encontrado para SB2017 é similar ao encontrado por Mota et al (2007). O valor de IN2018 é semelhante ao encontrado por Silva et al (2015) nos vinhos do Vale do São Francisco.

Os valores de ácido málico para IN2017 foram menores que SB2017, podendo se relacionar a alta temperatura diurna na região (JACKSON e LOMBARD, 1993). A razão entre ácido tartárico e málico em SB2017, IN2017 e SB2018 estão na faixa 
geralmente encontradas nas regiões tradicionais de produção de vinho de Bordeaux e Califórnia (BLOUIN e GUIMBERTEAU, 2004).

\section{2 - ANÁLISE DE COMPOSTOS VOLATEIS}

Foram coletadas amostras das principais etapas de elaboração do vinho: mosto, fermentação alcóolica, fermentação malolática, envase, 6 meses de envelhecimento e 12 meses de envelhecimento. Após serem analisadas, observouse que as etapas que mais influenciam o processo de elaboração do vinho quanto as diferenças na composição volátil, são as etapas de obtenção do mosto, envase e 12 meses de envelhecimento.

Ao todo, 103 compostos foram identificados, sendo 81 compostos em SB e 76 em IN. Desses 103 compostos, 54 foram identificados em ambas as regiões, 27 foram identificados somente em SB e 22 somente em IN (Tabela 4).

O maior grupo de compostos voláteis encontrado em ambas as regiões e em ambas as safras foi o grupo éster com 43 compostos, seguido do grupo álcool com 27 compostos voláteis. Resultado semelhante foi encontrado por (MOTA et al.; 2020) em plantas conduzidas sob dupla poda cultivadas em outra região do sudeste brasileiro. O grupo éster contribui para as notas frutadas no vinho (GONZÁLESBARREIRO et al. 2015). 
A análise de componentes principais mostra que há diferença entre os compostos encontrados no mosto, entre as regiões de São Bento do Sapucaí e Indaiatuba na safra de 2017 e 2018.

Figura 9. Score plot discriminativo como componente principal o mosto a diferença entre regiões na região de São Bento do Sapucaí e Indaiatuba na safra de 2017.
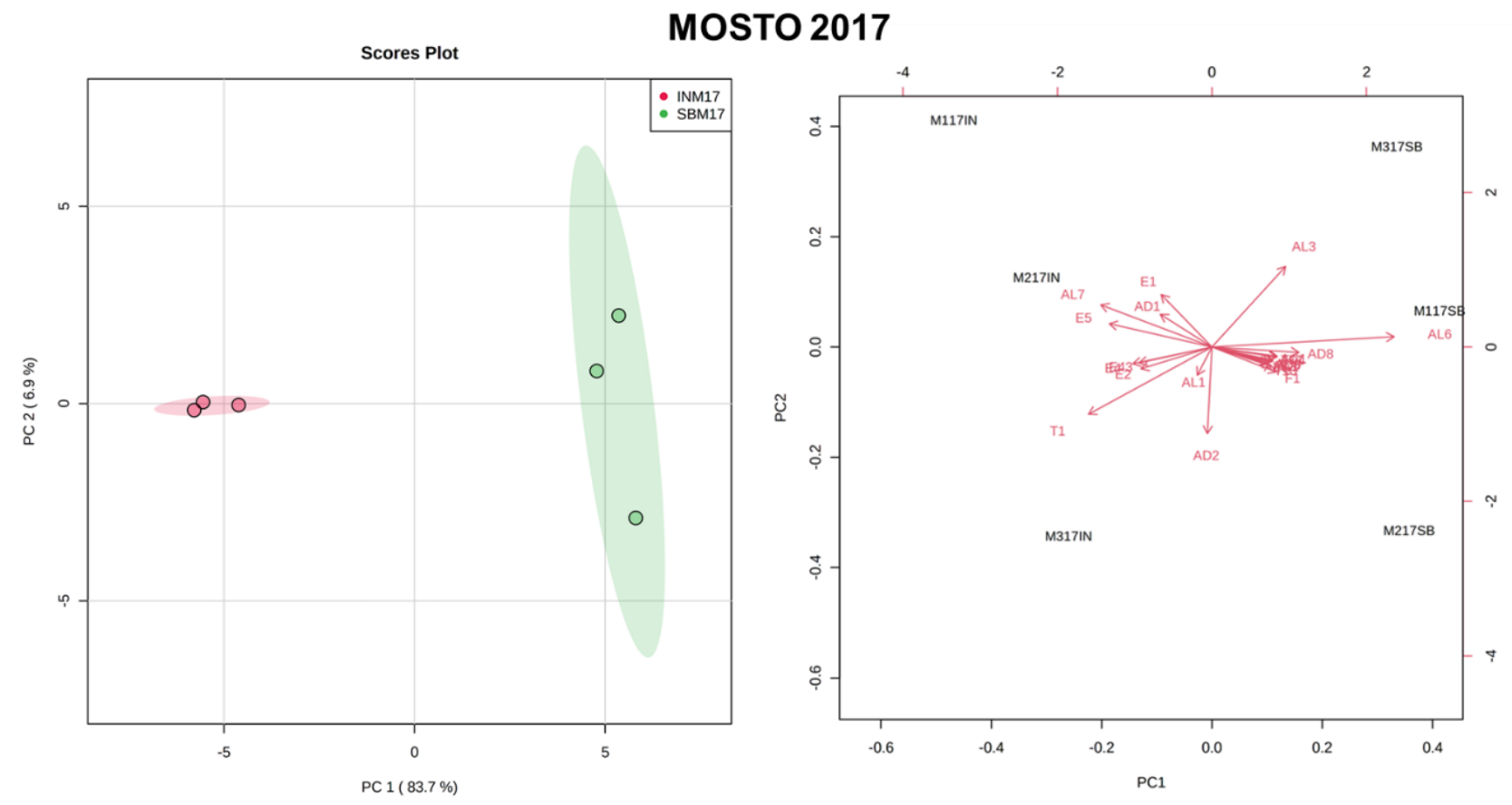

Figura 10. Score plot discriminativo como componente principal o mosto a diferença entre regiões na região de São Bento do Sapucaí e Indaiatuba na safra de 2018.

MOSTO 2018
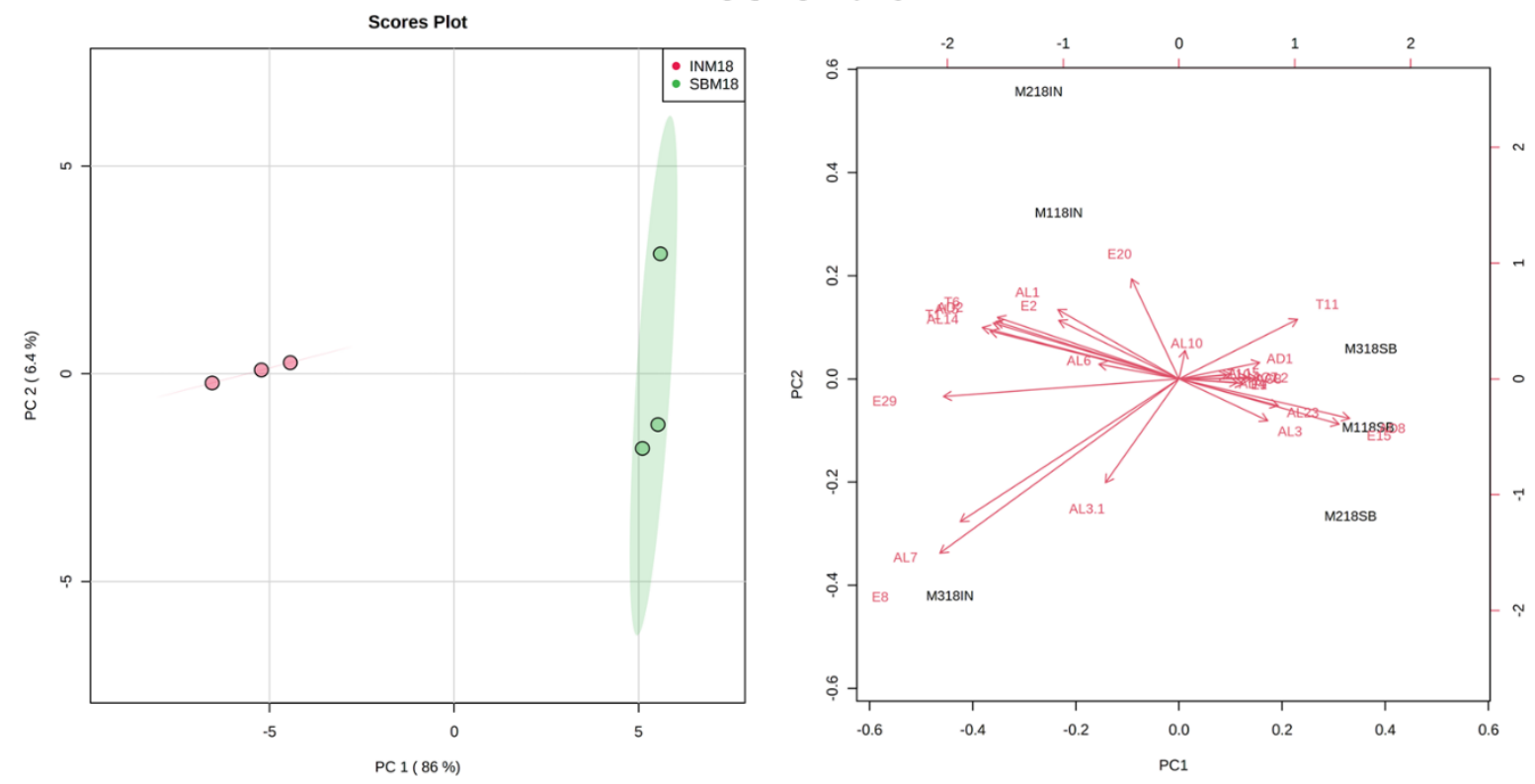

Os compostos que, aparentemente, mais influenciaram as diferenças entre os mostos produzidos com uvas de SB e IN em ambas as safras e em ambas as regiões 
foram: 1-Octen-3-ol (AL1), Phenylethyl Alcohol (AL3), 1-Hexanol (AL6), 1-Octanol (AL7), Ethyl hexanoate (E1), Ethyl Decanoate (E2), Isopentyl hexanoate (E15), Ethyl Dodecanoate (E43), Pentanal (AD1) e Nonanal (AD8).Os compostos encontrados são descritos por Mayr et al. (2014) Antalick et al. (2015) em vinhos australianos e por Marie et al (2019) em vinhos elaborados no Vale Du Rhonê - França. Os compostos encontrados somente no mosto em SB em ambas as regiões são: 3-Hexen-1-ol, (Z)(AL2), beta.-Phellandrene (T9), o-Cymene (T10), .alpha.-Phellandrene (T11), (furan2-yl) ethylene (T12) e 5-Hydroxymethylfurfural (F1). Já o composto encontrado somente em IN em ambas as safras foi o composto Terpinen-4-ol (T1). Esses compostos encontrados no mosto têm sua origem no metabolismo da própria variedade e são influenciados por fatores externos, como solo e clima (BELANCIC e AGOSIN.; 2000). Embora vários fatores possam influenciar as diferenças na composição volátil, os dados obtidos permitem supor que a dupla poda não influencia o metabolismo das bagas a ponto de produzir um perfil de compostos voláteis totalmente estranho ao esperado para um produto derivado de uvas Syrah.

O maior detalhamento sobre as diferenças nos teores relativos dos compostos identificados nas regiões, em todas as etapas de vinificação analisadas, bem como nas duas safras, pode ser acessado nos heat-maps construídos com os valores normalizados das áreas dos compostos no Anexo 2 
Tabela 4: Compostos voláteis identificados por classes nas etapas de elaboração do vinho com os respectivos CAS, código, nome do composto, descritor aromático (Análise por HS-SPME/GC-MS). Realizado na safra de 2017 e 2018 nas regiões de São Bento do Sapucaí (SB) e Indaiatuba (IN).

\begin{tabular}{|c|c|c|c|c|c|c|c|c|c|}
\hline \multirow{2}{*}{ CAS } & \multirow[t]{2}{*}{ Código } & \multirow{2}{*}{$\begin{array}{c}\text { Composto } \\
\text { Álcool }\end{array}$} & \multirow{3}{*}{$\begin{array}{l}\text { Descritor } \\
\text { aromático }\end{array}$} & $\begin{array}{c}\text { Mosto } \\
2017\end{array}$ & $\begin{array}{c}\text { Mosto } \\
2018 \\
\end{array}$ & Envase 2017 & Envase 2018 & 12 meses 2017 & 12 meses 2018 \\
\hline & & & & & & & & & \\
\hline $3391-86-4$ & AL1 & 1-Octen-3-ol & & & & & & & \\
\hline $928-96-1$ & AL2 & 3-Hexen-1-ol, (Z)- & Herbáceo & & & & & & \\
\hline $60-12-8$ & AL3 & Phenylethyl Alcohol & Especiaria & & & & & & \\
\hline 78-83-1 & AL4 & Isobutanol & Vinho & & & & & & \\
\hline $64-17-5$ & AL5 & Ethanol & Alcool & & & & & & \\
\hline $111-27-3$ & AL6 & 1-Hexanol & Herbáceo & & & & & & \\
\hline $111-87-5$ & AL7 & 1-Octanol & Frutado & & & & & & \\
\hline $111-70-6$ & AL8 & 1-Heptanol & Herbáceo & & & & & & \\
\hline $143-08-8$ & AL9 & 1-Nonanol & Floral & & & & & & \\
\hline $928-95-0$ & AL10 & 2-Hexen-1-ol, (E)- & Frutado & & & & & & \\
\hline $104-76-7$ & AL11 & 2-ethyl-1-hexanol & Floral & & & & & & \\
\hline $123-51-3$ & AL12 & Isoamyl Alcohol & Whiskey & & & & & & \\
\hline $71-36-3$ & AL13 & 1-Butanol & Adocicado & & & & & & \\
\hline $544-12-7$ & AL14 & 3-Hexen-1-ol & Herbáceo & & & & & & \\
\hline $818-49-5$ & AL15 & 4-Methyl-1-hexanol & Adocicado & & & & & & \\
\hline $501-94-0$ & AL16 & 4-hydroxyphenethyl alcohol & Floral & & & & & & \\
\hline $78-70-6$ & AL17 & Linalool & Floral & & & & & & \\
\hline $90-05-1$ & AL18 & Ortho-Guiacol & Adocicado & & & & & & \\
\hline $112-30-1$ & AL19 & 1-Decanol & Floral & & & & & & \\
\hline $628-99-9$ & AL20 & 2-Nonanol & Citrico & & & & & & \\
\hline $626-89-1$ & AL21 & 4-Methy-1-Pentanol & Nozes & & & & & & \\
\hline $142-50-7$ & AL22 & Cis-Nerolidol & Floral & & & & & & \\
\hline $71-41-0$ & AL23 & 1-Pentanol & Adocicado & & & & & & \\
\hline $1117-61-9$ & AL24 & (R)-(+)-beta-citronellol & Floral & & & & & & \\
\hline $100-51-6$ & AL25 & Benzyl alcohol & Floral & & & & & & \\
\hline $505-10-2$ & AL26 & Methionol & Adocicado & & & & & & \\
\hline $67-56-1$ & AL27 & Methy Alcohol & Alcool & & & & & & \\
\hline & & Terpenos & & & & & & & \\
\hline $562-74-3$ & T1 & Terpinen-4-ol & Pimenta & & & & & & \\
\hline $36431-72-8$ & $\mathrm{~T} 2$ & Theaspirane & Especiaria & & & & & & \\
\hline $100-42-5$ & T3 & Styrene & Floral & & & & & & \\
\hline $104-50-7$ & $\mathrm{~T} 4$ & Gamma-Octalactone & Coco & & & & & & \\
\hline 21391-99-1 & T5 & alpha-calacorene & Amadeirado & & & & & & \\
\hline $673-84-7$ & T6 & Allocimene & Especiaria & & & & & & \\
\hline $93-89-0$ & $\mathrm{~T} 7$ & Ethyl Benzoate & Fruta seca & & & & & & \\
\hline $13679-85-1$ & T8 & Blackberry thiophenone & Mirtilo & & & & & & \\
\hline $555-10-2$ & T9 & beta.-Phellandrene & Menta & & & & & & \\
\hline $527-84-4$ & T10 & o-Cymene & Citrico & & & & & & \\
\hline $99-83-2$ & T11 & alpha.-Phellandrene & Especiaria & & & & & & \\
\hline $1487-18-9$ & $\mathrm{~T} 12$ & (furan-2-y)ethylene & Café & & & & & & \\
\hline
\end{tabular}




\begin{tabular}{|c|c|c|c|c|c|c|c|c|c|}
\hline CAS & Código & Composto & $\begin{array}{l}\text { Descritor } \\
\text { aromático }\end{array}$ & $\begin{array}{l}\text { Mosto } \\
2017\end{array}$ & $\begin{array}{c}\text { Mosto } \\
2018\end{array}$ & Envase 2017 & Envase 2018 & 12 meses 2017 & 12 meses 2018 \\
\hline & & Éster & & & & & & & \\
\hline $123-66-0$ & E1 & Ethyl hexanoate & Fruta vermelha & & & & & & \\
\hline $110-38-3$ & E2 & Ethyl Decanoate & Cognac & & & & & & \\
\hline $111-11-5$ & E3 & Methyl octanoate & Fruta citrica & & & & & & \\
\hline $142-92-7$ & E4 & Hexyl acetate & Fruta vermelha & & & & & & \\
\hline $106-32-1$ & E5 & Ethy octanoate & Floral & & & & & & \\
\hline $105-54-4$ & E6 & Ethyl butanoate & Fruta madura & & & & & & \\
\hline $123-92-2$ & E7 & Isoamyl acetate & Fruta vermelha & & & & & & \\
\hline $106-30-9$ & E8 & Ethy Heptanoate & Cognac & & & & & & \\
\hline $123-25-1$ & E9 & Diethyl succinate & Frutado & & & & & & \\
\hline $141-78-6$ & E10 & Ethyl Acetate & Frutado & & & & & & \\
\hline $2035-99-6$ & E11 & Isoamy Octanoate & Frutado & & & & & & \\
\hline $103-45-7$ & E12 & Phenethy acetate & Floral doce & & & & & & \\
\hline $78-36-4$ & E13 & Linalyl butanoate & Mel & & & & & & \\
\hline $76649-16-6$ & E14 & Ethyl trans-4-decenoate & Fruta citrica & & & & & & \\
\hline $2198-61-0$ & E15 & Isopenty hexanoate & Frutado & & & & & & \\
\hline $628-63-7$ & E16 & Amyl Acetate & Frutado & & & & & & \\
\hline $103-52-6$ & E17 & Phenethyl Butyrate & Morango & & & & & & \\
\hline $112-06-1$ & E18 & Hepty Acetate & Pera & & & & & & \\
\hline $105-85-1$ & E19 & Citronelly Formate & Frutado & & & & & & \\
\hline $106-73-0$ & E20 & Methy Heptanoate & Padräo Intemo & & & & & & \\
\hline $118-61-6$ & E21 & Ethyl salicylate & Wintergreen & & & & & & \\
\hline $628-97-7$ & E22 & Ethyl Palmitate & Manteiga & & & & & & \\
\hline $638-11-9$ & E23 & Isopropyl butyrate & Abacaxi maduro & & & & & & \\
\hline $141-16-2$ & E24 & Citronelly butyrate & Rosa & & & & & & \\
\hline $124-06-1$ & E25 & Ethyl tetradecanoate & Lirio & & & & & & \\
\hline $119-36-8$ & E26 & Methyl salicylate & Menta & & & & & & \\
\hline $108-64-5$ & E27 & Ethyl sovalerate & Frutado & & & & & & \\
\hline $110-19-0$ & E28 & Isobuty ester & Pera & & & & & & \\
\hline $97-64-3$ & E29 & Ehty lactate & Caramelo & & & & & & \\
\hline $41114-00-5$ & E30 & Ethyl Pentadecanoate & Mel & & & & & & \\
\hline $7460-74-4$ & E31 & 2-Phenethyl Valerate & Rosa & & & & & & \\
\hline $5451-52-5$ & E32 & Decyl Formate & Madresilva & & & & & & \\
\hline $659-70-1$ & E33 & Isoamyl Isovalerate & Maça madura & & & & & & \\
\hline $617-05-0$ & E34 & Ethyl Vanillate & Defumado & & & & & & \\
\hline $7452-79-1$ & E35 & Ethyl 2 methyl butyrate & Frutado & & & & & & \\
\hline $106-27-4$ & E36 & Isoamyl Butyrate & Damasco & & & & & & \\
\hline $120-50-3$ & E37 & Isobutyl Benzoate & Frutado & & & & & & \\
\hline $105-37-3$ & E38 & Propanoic acid, ehtyl ester & Frutado & & & & & & \\
\hline $2306-91-4$ & E39 & Isoamyl Decanoate & Frutado & & & & & & \\
\hline $57943-67-6$ & E40 & Phenethyl nonanoate & Frutado & & & & & & \\
\hline $67233-91-4$ & E41 & Ethyl 9-decenoate & Frutado & & & & & & \\
\hline $614-99-3$ & E42 & Ethyl 2-furoate & Floral & & & & & & \\
\hline $106-33-2$ & E43 & Ethyl Dodecanoate & Floral & & & & & & \\
\hline
\end{tabular}

Ethyl Dodecanoate 


\begin{tabular}{|c|c|c|c|c|c|c|c|c|c|}
\hline CAS & Código & Composto & $\begin{array}{l}\text { Descritor } \\
\text { aromático }\end{array}$ & $\begin{array}{c}\text { Mosto } \\
2017\end{array}$ & $\begin{array}{c}\text { Mosto } \\
2018\end{array}$ & Envase 2017 & Envase 2018 & 12 meses 2017 & 12 meses 2018 \\
\hline & & Aldeido & & & & & & & \\
\hline $110-62-3$ & AD1 & Pentanal & Fruta seca & & & & & & \\
\hline $6728-26-3$ & AD2 & 2-Hexenal, (E)- & Banana & & & & & & \\
\hline $100-52-7$ & AD3 & Benzaldehyde & Cereja & & & & & & \\
\hline $66-25-1$ & AD4 & Hexanal & Herbáceo & & & & & & \\
\hline $123-29-5$ & AD5 & Nonanoic acid, ethyl ester & Floral & & & & & & \\
\hline $75-07-0$ & AD6 & Ethanal & Frutado & & & & & & \\
\hline $112-31-2$ & AD7 & Decanal & Citrico & & & & & & \\
\hline $124-19-6$ & AD8 & Nonanal & Floral & & & & & & \\
\hline & & Acetonas & & & & & & & \\
\hline $110-93-0$ & AC1 & 5-Hepten-2-one, 6 -methy- & Ftura citrica & & & & & & \\
\hline $23726-93-4$ & $\mathrm{AC} 2$ & Beta-Damascenone & Tabaco & & & & & & \\
\hline $96-48-0$ & $\mathrm{AC} 3$ & Butyrolactone & Manteiga & & & & & & \\
\hline $6901-97-9$ & $\mathrm{AC} 4$ & Alpha-lonone & Floral & & & & & & \\
\hline $78-94-4$ & AC5 & Methyl vinyl ketone & Adocicado & & & & & & \\
\hline 8013-90-9 & AC6 & lonone & Amadeirado & & & & & & \\
\hline $110-43-0$ & $\mathrm{AC7}$ & 2-Heptanone & Herbáceo & & & & & & \\
\hline $14073-97-3$ & AC8 & I-Menthone & Menta & & & & & & \\
\hline & & Furanóide & & & & & & & \\
\hline $67-47-0$ & F1 & 5-Hydroxymethyifurfural & Manteiga & & & & & & \\
\hline & & Ácidos & & & & & & & \\
\hline $124-07-2$ & ACD1 & Octanoic acid & Herbáceo & & & & & & \\
\hline $105-43-1$ & ACD2 & Pentanoic acid, 3-methyl- & Herbáceo & & & & & & \\
\hline $334-48-5$ & ACD3 & Decanoic Acid & Ranço & & & & & & \\
\hline $109-52-4$ & ACD4 & Pentanoic acid & Ranço & & & & & & \\
\hline
\end{tabular}

São Bento do Sapucai Indaiatuba 
A análise de componentes principais mostra que há diferença entre os compostos encontrados no envase, entre as regiões de São Bento do Sapucaí e Indaiatuba na safra de 2017 e 2018.

Figura 11. Score plot discriminativo como componente principal o envase a diferença entre regiões na região de São Bento do Sapucaí e Indaiatuba na safra de 2017.
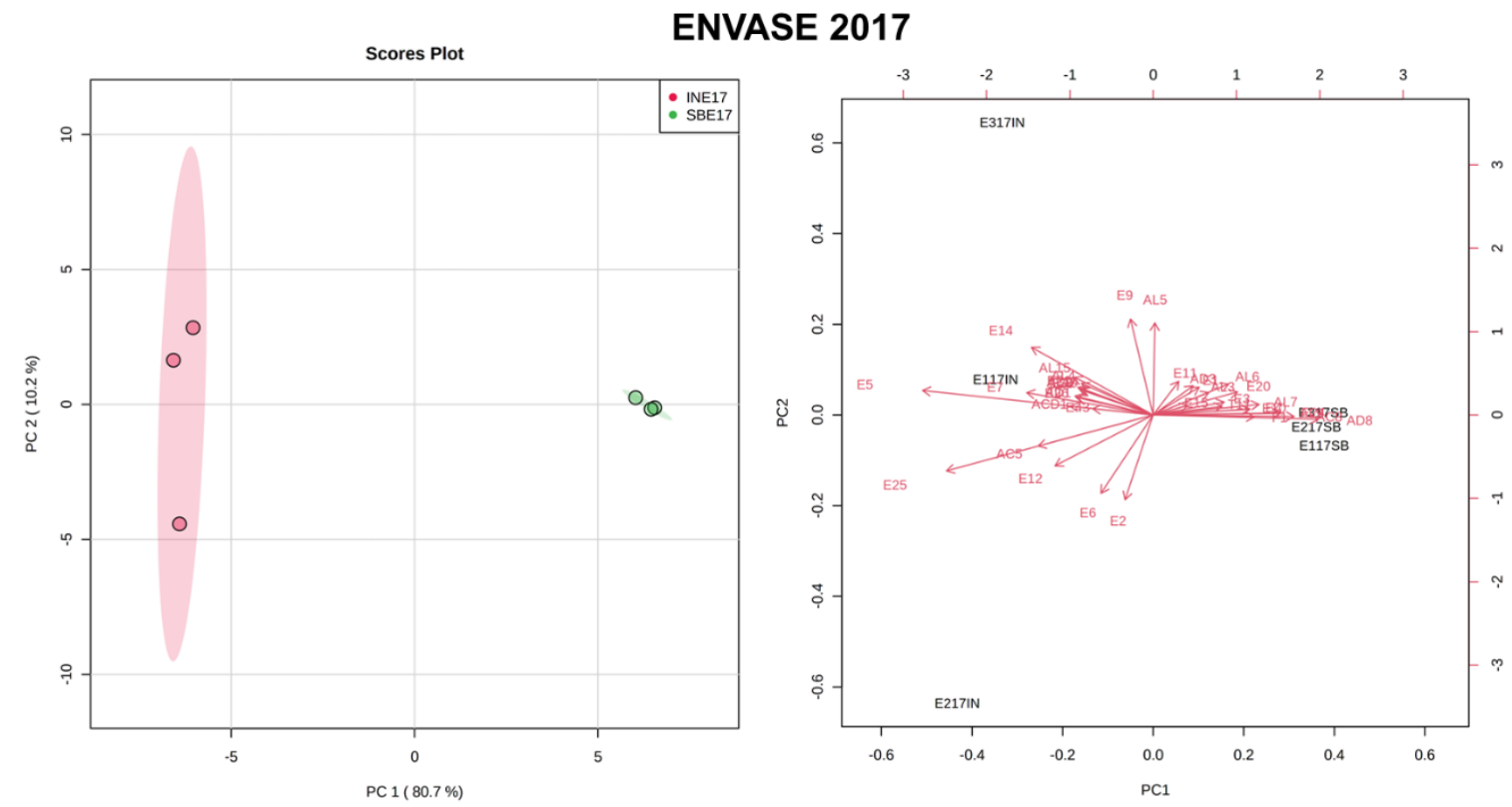

Figura 12. Score plot discriminativo como componente principal o envase a diferença entre regiões na região de São Bento do Sapucaí e Indaiatuba na safra de 2018.

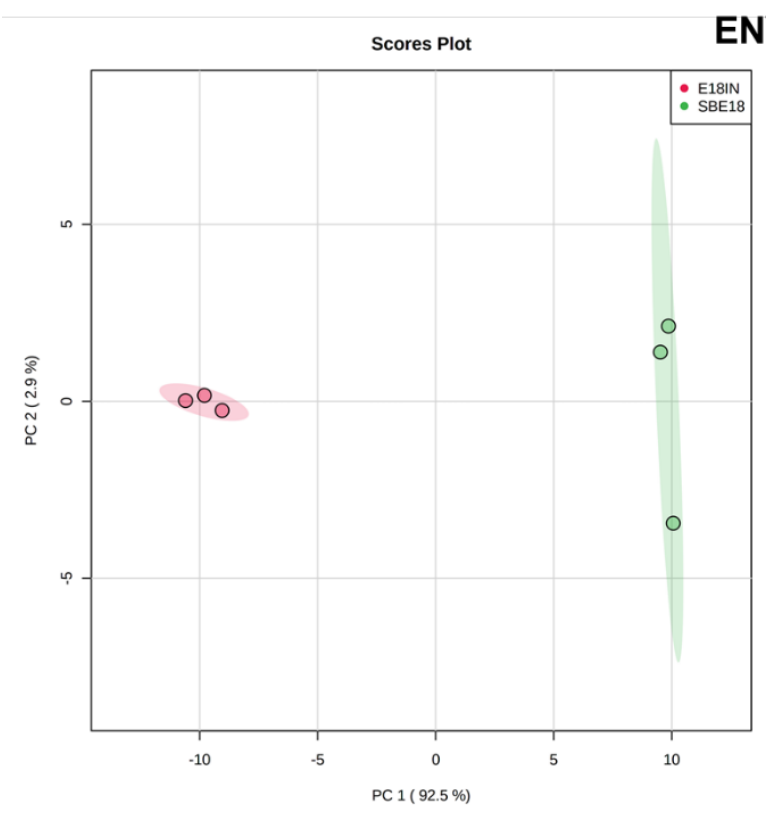

ENVASE 2018

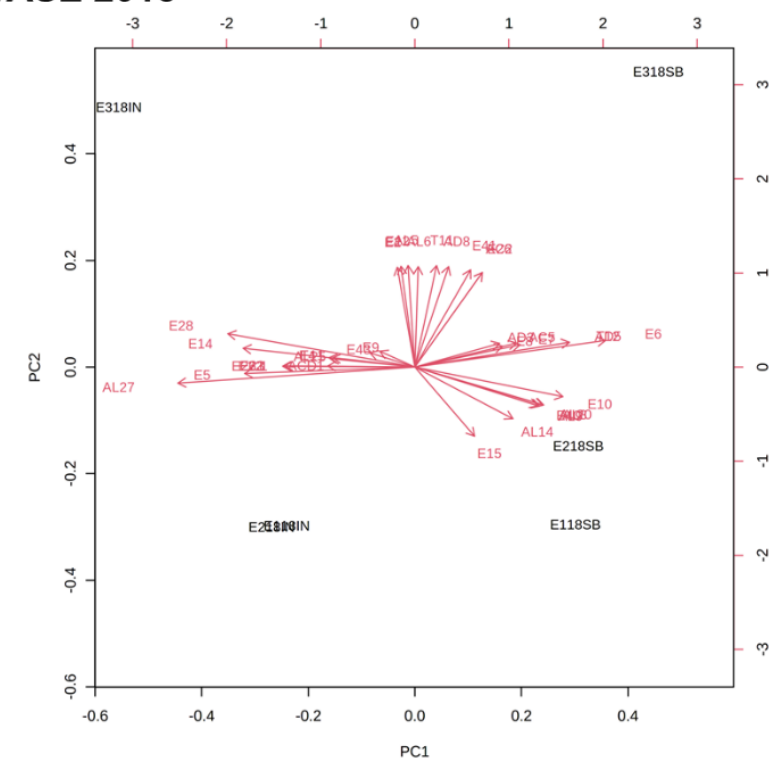

Os compostos formados na fermentação alcoólica e na fermentação malolática que tiveram maior impacto na diferenciação das amostras do envase e 
envelhecimento em garrafa por 12 meses em SB, em ambas as safras foram: Isobutanol (AL4), Ethanol (AL5), 1-Nonanol (AL9), Ethyl butanoate (E6), Isoamyl acetate (E7), Diethyl succinate (E9), Phenethyl acetate (E12) e Ehtyl trans 4decenoate (E14). Enquanto em IN foram: Isobutanol (AL4), Ethanol (AL5), Ethyl butanoate (E6), Isoamyl acetate (E7), Diethyl Succinate (E9), Phenethyl acetate (E12), Ethyl trans-4-decenoate (E14), Ethyl salicylate (E21), Ethyl Palmitate (E22), Methyl salicylate (E26), Isobutyl ester (E28), Methyl vinyl ketone (AC5), Octanoic acid (ACD1). 1-Nonanol (AL9) foi encontrado somente em SB, porém esse composto foi encontrado em outros vinhos de inverno da região sudeste como mostra (MOTA et al, 2020).

A análise de componentes principais mostra que há diferença entre os compostos encontrados no envelhecimento, entre as regiões de São Bento do Sapucaí e Indaiatuba na safra de 2017 e 2018.

Figura 13. Score plot discriminativo como componente principal o envelhecimento a diferença entre regiões na região de São Bento do Sapucaí e Indaiatuba na safra de 2017.

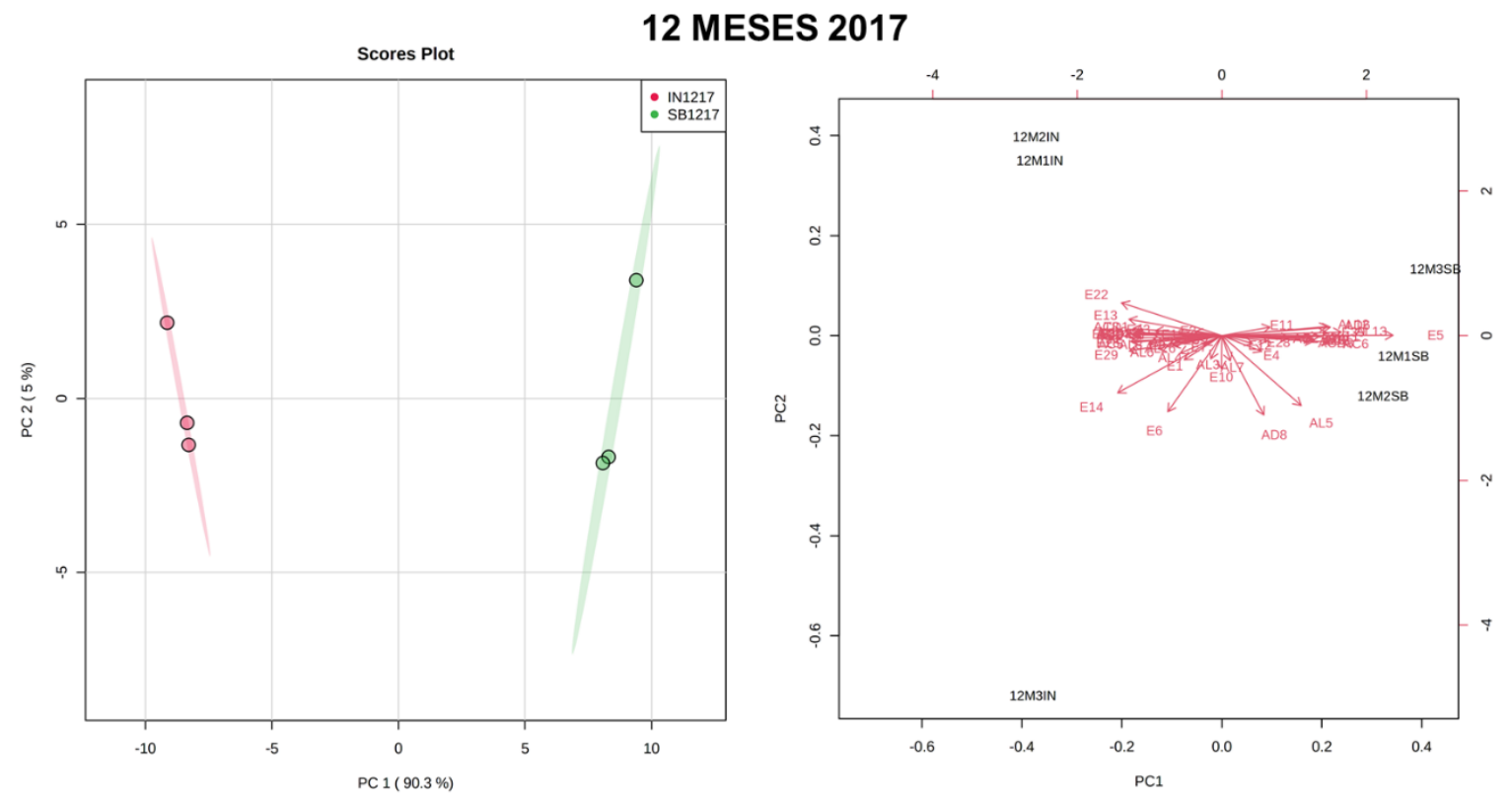


Figura 14. Score plot discriminativo como componente principal o envelhecimento a diferença entre regiões na região de São Bento do Sapucaí e Indaiatuba na safra de 2018.
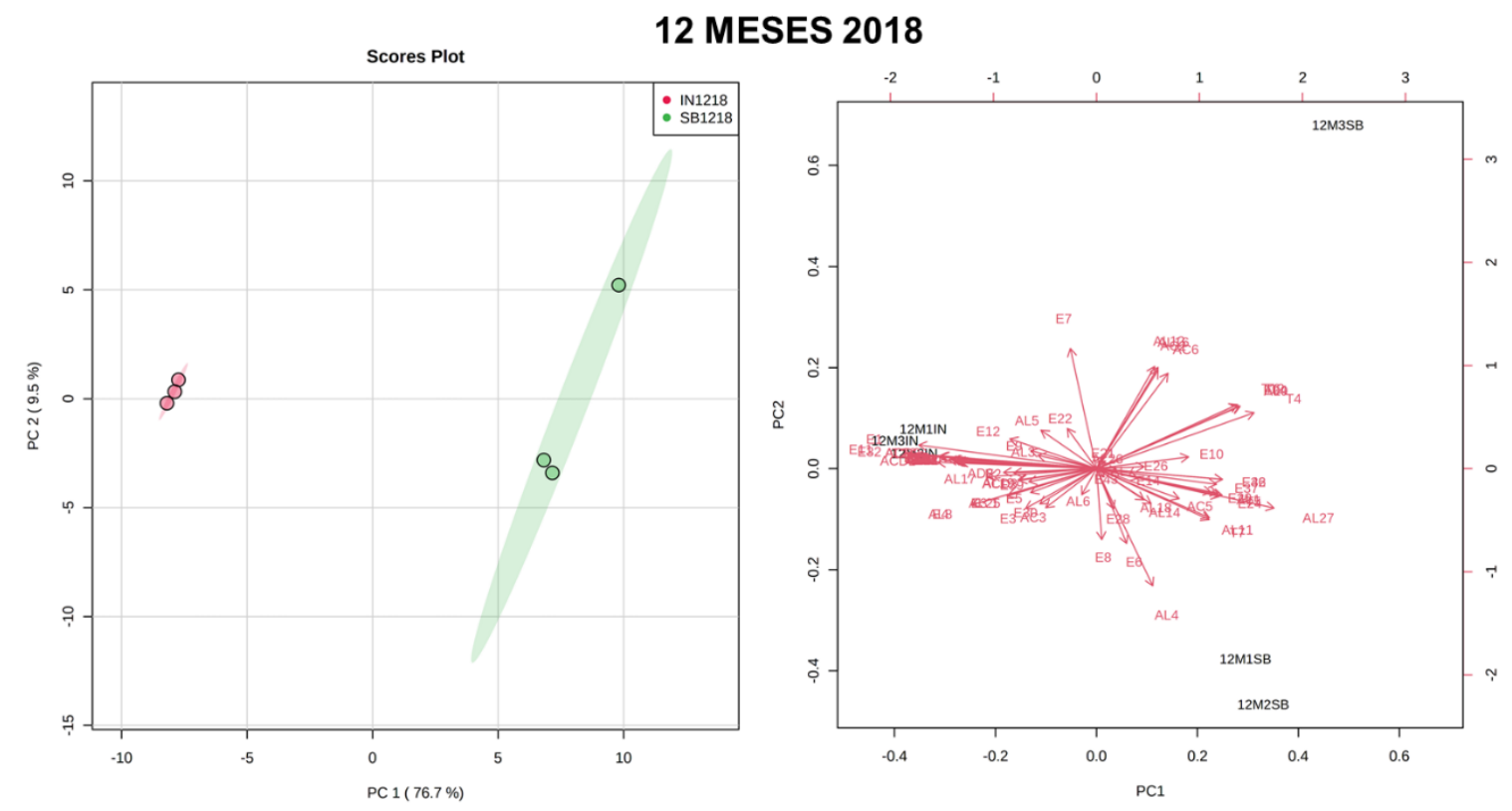

Os compostos com maior influência na separação das amostras dos vinhos no envelhecimento em SB, formados a partir de combinações ocorridas dentro da garrafa, foram: 2-ethyl-1-hexanol (AL11), Isoamyl Alcohol (AL12), (R)-(+)-betacitronellol (AL24), Isoamyl Decanoate (E39), Ethyl 2-furoate (E42), Butyrolactone (AC3), Beta-Damascenone (AC2) e lonone (AC6). Enquanto em IN foram: Benzyl alcohol (AL25), Methionol (AL26), Methyl Alcohol (AL27), Blackberry thiophenone (T8), Linalyl butanoate (E13), Ethyl 2 methyl butyrate (E35), Propanoic acid ehtyl ester (E38), Decanal (AD7), Beta-Damascenone (AC2), lonone (AC6), e Pentanoic acid, 3methyl- (ACD2). Os compostos característicos de envelhecimento nos vinhos encontrados, como a Beta-Damascenone, são formados por reações enzimáticas de carotenóides que são posteriormente submetidos a reações catalíticas durante o envelhecimento do vinho (BRILLANTE et al. 2018)

Os terpenos são sintetizados durante a maturação da uva e são responsáveis pelos descritores de pimenta característicos da variedade Syrah. Nesse estudo, os compostos Terpinen-4-ol (T1), Theaspirane (T2), Allocimene (T6) e alpha- 
Phellandrene (T11) foram identificados como descritores de pimenta. Entretanto os únicos que são identificados no vinho após 12 meses de envelhecimento são os compostos Allocimene (T6) em SB e Theaspirane (T2) em IN. O composto característico pelo aroma de pimenta Rotundona não foi encontrado nesse estudo e em outro estudo com vinhos da região sudeste com colheita de inverno como mostra (MOTA et al 2020), sendo necessário mais estudos a respeito para confirmar se isto é um efeito significativo ocasionado pela dupla poda ou outros tratos agronômicos ou ainda por outros fatores associados as linhagens cultivadas no país e fatores edafoclimáticos.

Através de uma análise qualitativa, foi observado que ao longo do processo o mosto perde/transforma parte de seus compostos devido às variáveis da vinificação, como oxidação, catálise enzimática, variáveis associadas a levedura, entre outros (ILC et al. 2016). Os compostos formados a partir das fermentações se conservam até o envelhecimento e novos compostos são acrescentados nas etapas seguintes de elaboração (figura 15).

Figura 15: Análise qualitativa dos compostos ao longo do processo de elaboração nas regiões de São Bento do Sapucaí e Indaiatuba na safra de 2018.
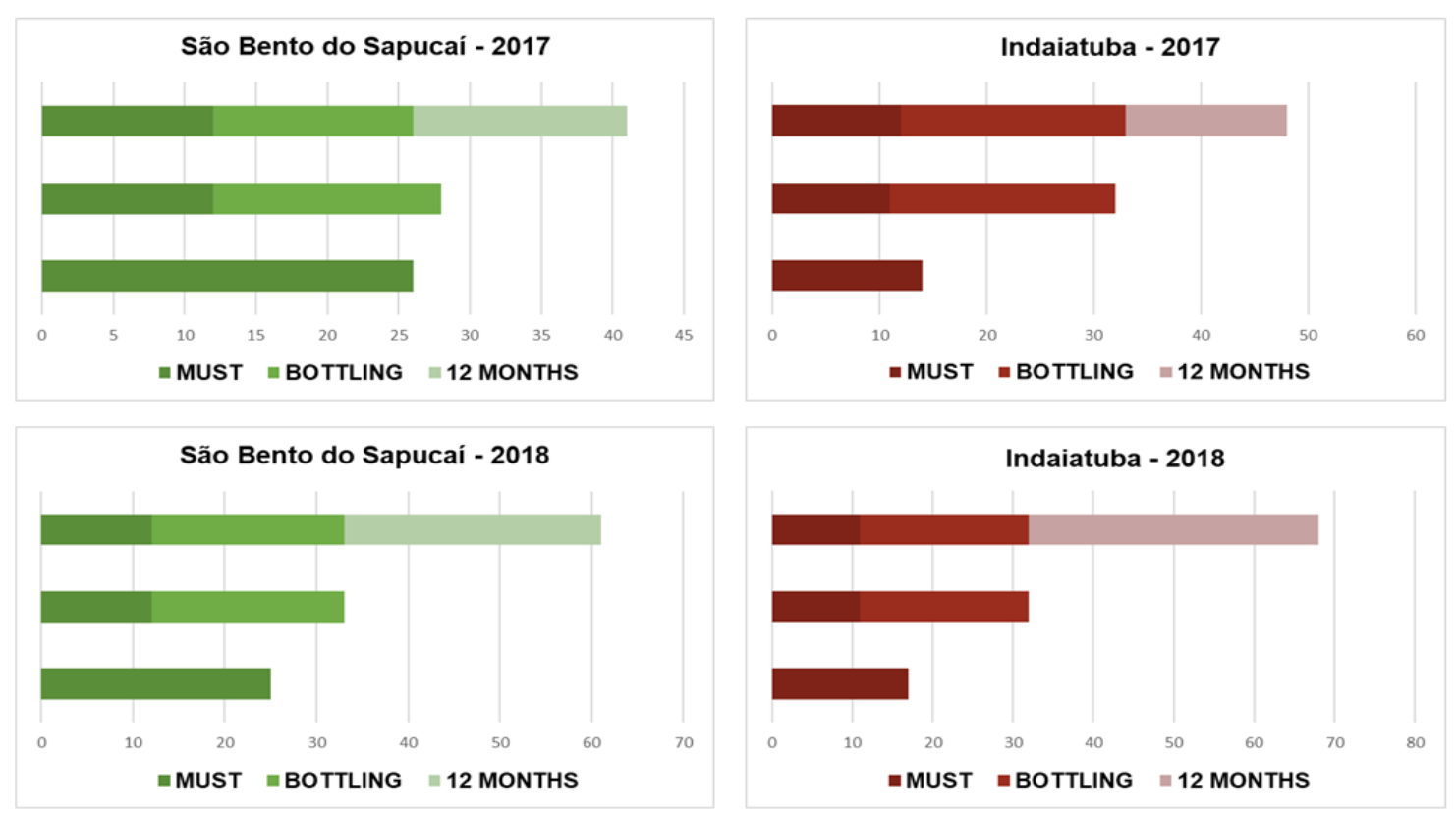
Oito compostos foram identificados em ambas as regiões e em ambas as safras, do mosto até 12 meses de envelhecimento em garrafa. Esses compostos podem representar possíveis descritores de vinhos da variedade Syrah cultivada no estado de São Paulo - Brasil, uma vez que esses compostos são da própria uva e permaneceram durante todo o processo: Phenylethyl Alcohol (AL3), 1-Hexanol (AL6), 1-Octanol (AL7), Ethyl hexanoate (E1), Ethyl Decanoate (E2), Isopentyl hexanoate (E15), Ethyl Dodecanoate (E43I) e Nonanal (AD8). Esses compostos encontrados são também descritos por outros autores como (MAYR et al. 2014) (ANTALICK et al. 2015) em vinhos australianos, por Brillante et al. 2018 em vinhos da Califórnia - EUA e Hunter e Volschenk, 2018 em vinhos da África do Sul. Estes compostos representam os aromas percebidos pelo consumidor final e, são associados a qualidade e identidade do vinho (WELDEGERGIS et al, 2011).

Em resumo, as análises agronômicas mostraram que os valores encontrados são parecidos com outras regiões produtoras no Brasil e em outros países. O ácido málico é menor em Indaiatuba por apresentar altas temperaturas e maiores em São Bento do Sapucaí.

Pode-se observar que apesar da semelhança na composição volátil encontrada, existe diferença entre as regiões de São Bento do Sapucaí e Indaiatuba assim como entre as safras de 2017 e 2018 . Este estudo mostra que uma parte dos compostos que se tem na uva (pré-fermentativos) se perde/transforma em outros compostos ao longo do processo de elaboração. A maior parte dos compostos do vinho são formados a partir do processo de fermentação alcoólica e fermentação malolática, mas o envelhecimento também contribui para a formação de compostos voláteis. Os ésteres forma os compostos mais evidentes em ambas as regiões, contribuindo para aromas do tipo floral e frutado. 


\section{5- CONCLUSÃO}

Apesar dos vinhos serem produzidos em novas regiões com ciclo invertido de produção, eles apresentam compostos e descritores esperados para a variedade. Este é um resultado desejado, mas que ainda merece maior aprofundamento. É possível supor que a inversão de ciclo deva provocar alterações significativas no metabolismo da planta e dos frutos especialmente. Contudo, a extensão destas modificações, em termos de detalhamento molecular, ainda é pouco claro e seu conhecimento muito necessário, visto que o volume de produção de vinhos derivados deste sistema de produção vem crescendo rapidamente, particularmente no Brasil. Este é um diferencial importante para o vinho produzido no país e que começa a chamar a atenção do mercado mundial.

Dado o cuidado empregado neste estudo de ter o maior número de variáveis similares entre as vinificações das uvas das duas regiões, foi possível caracterizar compostos voláteis exclusivos de cada região vinícola. Estes compostos podem representar potenciais marcadores químicos dos vinhos destas regiões, auxiliando futuras propostas de certificação de origem geográfica. 


\section{6- ANEXOS:}

\section{1 - Anexo 1}

\begin{tabular}{|c|c|c|c|c|c|c|c|c|c|c|c|}
\hline 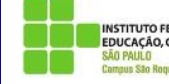 & 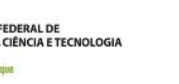 & & & RELATÓ & O DE VI & IIFICAÇÃC & & & & & \\
\hline PROJETO: & \multicolumn{2}{|c|}{ Mestrado Lucas - 2017} & & & & & & & & & \\
\hline REGIÃO: & \multicolumn{2}{|c|}{ São Bento do Sapucaí } & & & & & & & & & \\
\hline PESO: & $18,25 \mathrm{Kg}$ & & & & & & & & & & \\
\hline TANQUE: & Pirex $25 \mathrm{~L}(1)$ & & & & & & & & & & \\
\hline \multicolumn{12}{|c|}{ ANÁLISES } \\
\hline 'BRIX: & \multicolumn{2}{|l|}{21,5} & & & & & & & & & \\
\hline DENSIDADE: & \multicolumn{2}{|l|}{1090} & & & & & & & & & \\
\hline ACIDEZ TOTAI & \multicolumn{2}{|l|}{100} & & & & & & & & & \\
\hline $\mathrm{pH}:$ & \multicolumn{2}{|l|}{2,9} & & & & & & & & & \\
\hline \multicolumn{12}{|c|}{ ACOMPANHAMENTO DIÁRIO DE VINIFICAÇÃO } \\
\hline DATA & HORA & DENSID. & TEMP. & DATA & HORA & DENSID. & TEMP. & DATA & HORA & DENSID. & TEMP. \\
\hline $09 / 08$ & $8 \mathrm{~h}$ & 1094 & 17 & & & & & & & & \\
\hline $10 / 08$ & $8 \mathrm{~h}$ & 1089 & 21 & & & & & & & & \\
\hline $11 / 08$ & $8 \mathrm{~h}$ & 1075 & 20 & & & & & & & & \\
\hline $12 / 08$ & $8 \mathrm{~h}$ & 1055 & 20 & & & & & & & & \\
\hline $13 / 08$ & $8 \mathrm{~h}$ & 1035 & 20 & & & & & & & & \\
\hline $14 / 08$ & $8 \mathrm{~h}$ & 1014 & 20 & & & & & & & & \\
\hline $15 / 08$ & $8 \mathrm{~h}$ & 1008 & 18 & & & & & & & & \\
\hline $16 / 08$ & $8 \mathrm{~h}$ & 1001 & 18 & & & & & & & & \\
\hline \multirow[t]{3}{*}{$17 / 08$} & $8 \mathrm{~h}$ & 994 & 20 & & & & & & & & \\
\hline & & & & & & & & & & & \\
\hline & & & & & & & & & & & \\
\hline \multicolumn{12}{|c|}{ VINIFICAÇÃO } \\
\hline COLHEITA: & \multicolumn{2}{|l|}{$\begin{array}{l}06 / 08 / 2017 \\
\end{array}$} & & & & & & & & & \\
\hline DESENGACE: & \multicolumn{2}{|l|}{$07 / 08 / 2017$} & & & & & & & & & \\
\hline OPF: & \multirow{2}{*}{\multicolumn{2}{|c|}{$\begin{array}{c}- \\
08 / 08 / 2017\end{array}$}} & & & & & & & & & \\
\hline INÍCIO F.A. : & 08/08/2017 & & & & & & & & & & \\
\hline FIM F.A. : & \multicolumn{2}{|l|}{$17 / 08 / 2017$} & & & & & & & & & \\
\hline DESCUBE: & \multicolumn{2}{|l|}{$17 / 08 / 2017$} & & & & & & & & & \\
\hline \multicolumn{12}{|l|}{ FML: } \\
\hline \multicolumn{12}{|c|}{ ESTABILIZAÇã 15 dias por -5 으 } \\
\hline & & & & & & & & & & & \\
\hline LEVEDURA: & \multicolumn{3}{|c|}{ 25g/HI (Maurivin Awri1503) } & & & & & & & & \\
\hline ENZIMA: & \multicolumn{2}{|c|}{ 2g/hl (Colorpect) } & & & & & & & & & \\
\hline \multicolumn{12}{|c|}{ CLARIFICANTE: } \\
\hline $\mathrm{SO}_{2}$ INICIAL: & $80 \mathrm{mg} / \mathrm{L}$ & & & & & & & & & & \\
\hline \multicolumn{12}{|c|}{ OBSERVAÇÕES E CORREÇÕES AO LONGO DO PROCESSO } \\
\hline \multicolumn{4}{|c|}{ Após F.M -> correção do SO2 para 35 mg/L } & & & & & & & & \\
\hline Envase -> corr & reção do SO2 pa & ara $35 \mathrm{mg} / \mathrm{L}$ & & & & & & & & & \\
\hline & & & & & & & & & & & \\
\hline
\end{tabular}


RELATÓRIO DE VINIFICAÇÃO

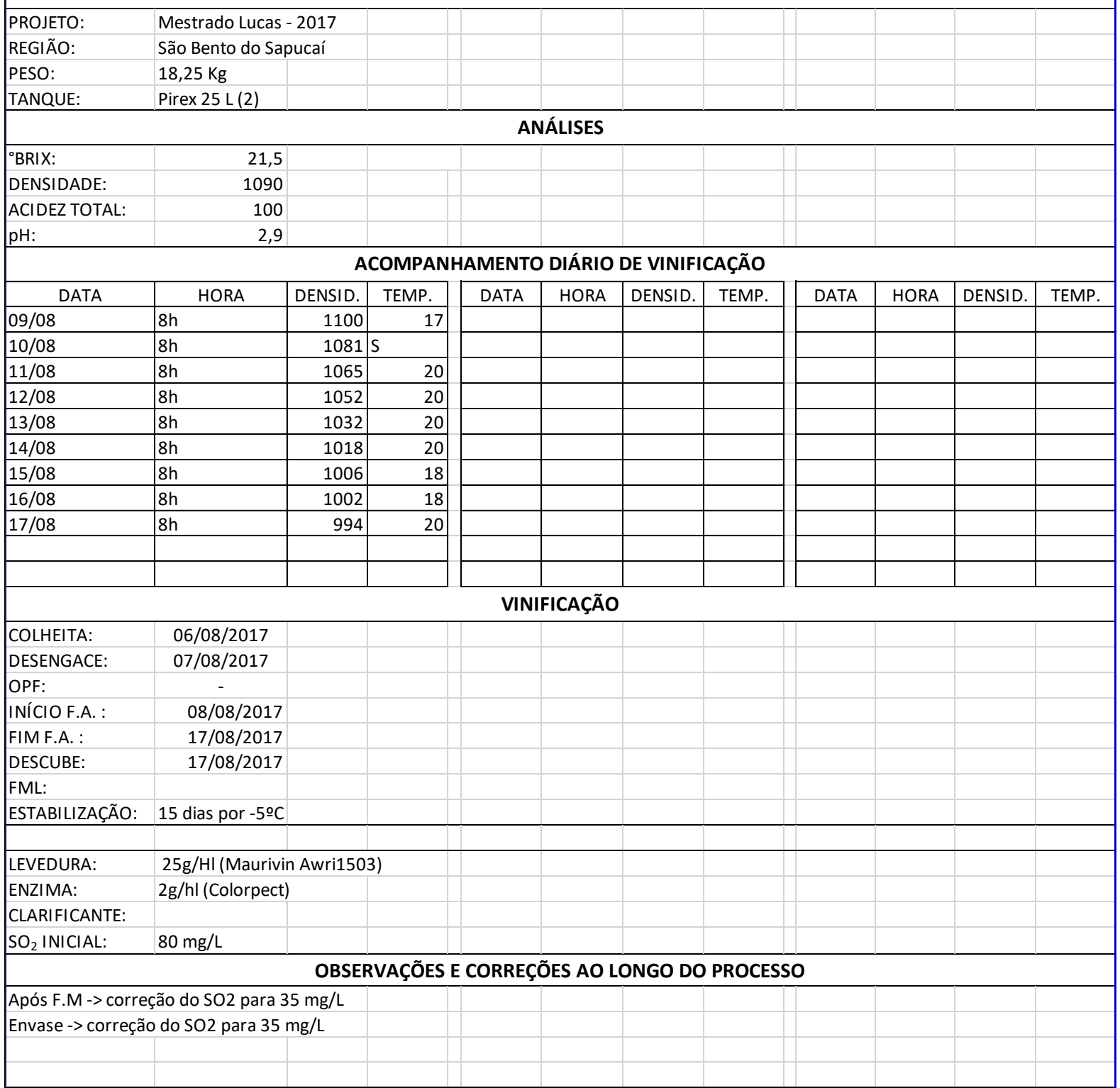


RELATÓRIO DE VINIFICAÇÃO

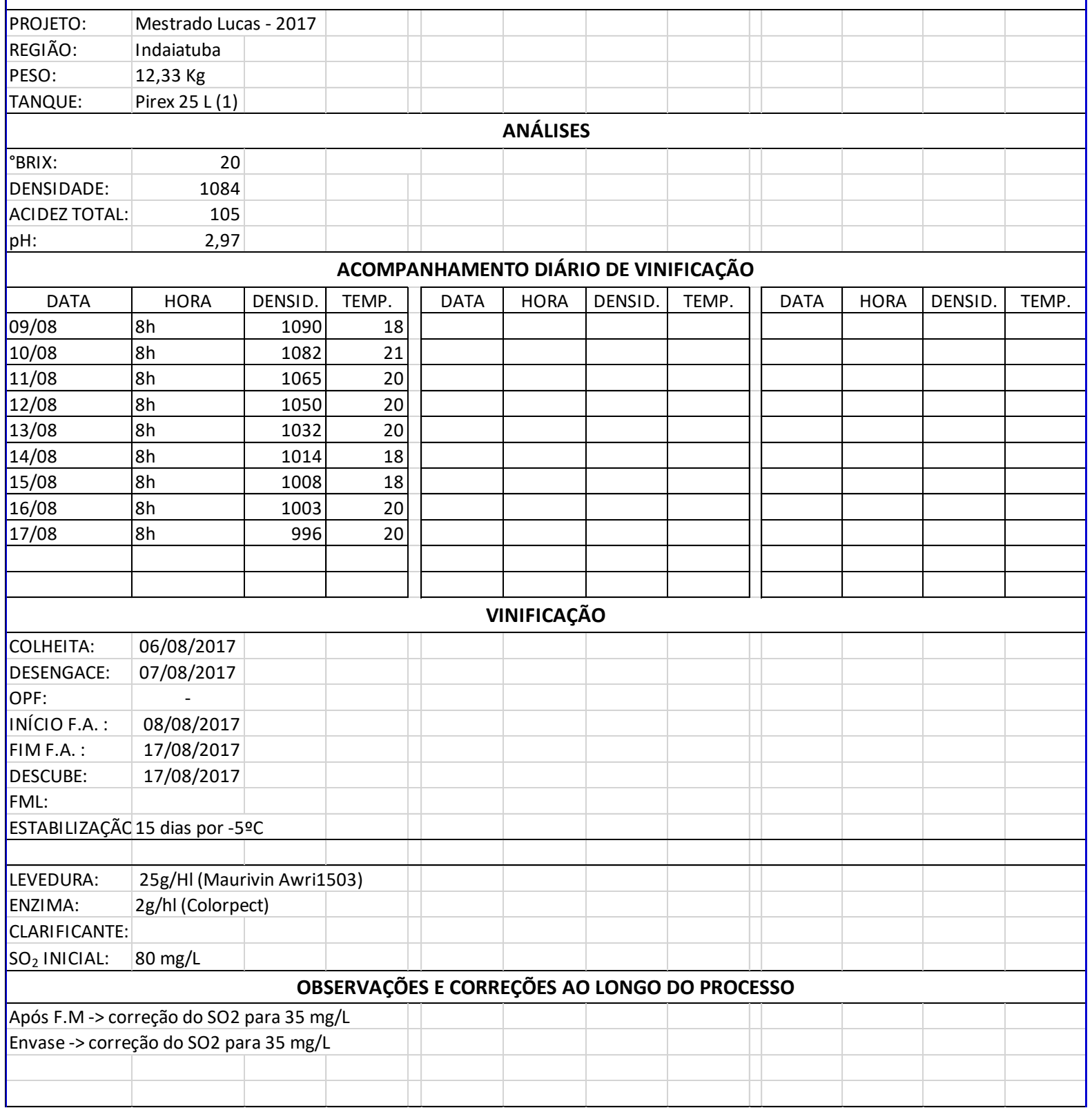


RELATÓRIO DE VINIFICAÇÃO

\begin{tabular}{|c|c|c|c|c|c|c|c|c|c|c|c|}
\hline PROJETO: & Mestrado Luca & as - 2017 & & & & & & & & & \\
\hline REGIÃO: & Indaiatuba & & & & & & & & & & \\
\hline PESO: & $12,33 \mathrm{Kg}$ & & & & & & & & & & \\
\hline TANQUE: & Pirex $25 \mathrm{~L}(1)$ & & & & & & & & & & \\
\hline \multicolumn{12}{|c|}{ ANÁLISES } \\
\hline${ }^{\circ} \mathrm{BRIX}$ & \multicolumn{2}{|l|}{20} & & & & & & & & & \\
\hline DENSIDADE: & \multicolumn{2}{|l|}{1084} & & & & & & & & & \\
\hline ACIDEZ TOTAL: & \multirow{2}{*}{\multicolumn{2}{|c|}{$\begin{array}{r}105 \\
297\end{array}$}} & & & & & & & & & \\
\hline pH: & & & & & & & & & & & \\
\hline \multicolumn{12}{|c|}{ ACOMPANHAMENTO DIÁRIO DE VINIFICAÇÃO } \\
\hline DATA & HORA & DENSID. & TEMP. & DATA & HORA & DENSID. & TEMP. & DATA & HORA & DENSID. & TEMP. \\
\hline $09 / 08$ & $8 \mathrm{~h}$ & 1090 & 17 & & & & & & & & \\
\hline $10 / 08$ & $8 \mathrm{~h}$ & 1080 & 21 & & & & & & & & \\
\hline $11 / 08$ & $8 \mathrm{~h}$ & 1067 & 20 & & & & & & & & \\
\hline $12 / 08$ & $8 \mathrm{~h}$ & 1050 & 20 & & & & & & & & \\
\hline $13 / 08$ & $8 \mathrm{~h}$ & 1034 & 20 & & & & & & & & \\
\hline $14 / 08$ & $8 \mathrm{~h}$ & 1016 & 18 & & & & & & & & \\
\hline $15 / 08$ & $8 \mathrm{~h}$ & 1012 & 18 & & & & & & & & \\
\hline $16 / 08$ & $8 \mathrm{~h}$ & 1003 & 20 & & & & & & & & \\
\hline \multirow[t]{3}{*}{$17 / 08$} & $8 \mathrm{~h}$ & 996 & 20 & & & & & & & & \\
\hline & & & 19,3333 & & & & & & & & \\
\hline & & & & & & & & & & & \\
\hline \multicolumn{12}{|c|}{ VINIFICAÇÃO } \\
\hline COLHEITA: & $06 / 08 / 2017$ & & & & & & & & & & \\
\hline DESENGACE: & $07 / 08 / 2017$ & & & & & & & & & & \\
\hline OPF: & - & & & & & & & & & & \\
\hline INÍCIO F.A. : & 08/08/2017 & & & & & & & & & & \\
\hline FIM F.A. : & $17 / 08 / 2017$ & & & & & & & & & & \\
\hline DESCUBE: & $17 / 08 / 2017$ & & & & & & & & & & \\
\hline \multicolumn{12}{|l|}{ FML: } \\
\hline \multicolumn{12}{|c|}{ ESTABILIZAÇÃC 15 dias por $-5^{\circ} \mathrm{C}$} \\
\hline & & & & & & & & & & & \\
\hline LEVEDURA: & \multicolumn{3}{|c|}{ 25g/HI (Maurivin Awri1503) } & & & & & & & & \\
\hline ENZIMA: & \multicolumn{2}{|c|}{$2 \mathrm{~g} / \mathrm{hl}$ (Colorpect) } & & & & & & & & & \\
\hline \multicolumn{12}{|l|}{ CLARIFICANTE: } \\
\hline $\mathrm{SO}_{2}$ INICIAL: & $80 \mathrm{mg} / \mathrm{L}$ & & & & & & & & & & \\
\hline \multicolumn{12}{|c|}{ OBSERVAÇÕES E CORREÇÕES AO LONGO DO PROCESSO } \\
\hline \multicolumn{12}{|c|}{ Após F.M -> correção do SO2 para $35 \mathrm{mg} / \mathrm{L}$} \\
\hline \multicolumn{12}{|c|}{ Envase -> correção do SO2 para $35 \mathrm{mg} / \mathrm{L}$} \\
\hline & & & & & & & & & & & \\
\hline & & & & & & & & & & & \\
\hline
\end{tabular}


1.

RELATÓRIO DE VINIFICAÇÃO

\begin{tabular}{|c|c|c|c|c|c|c|c|c|c|c|c|}
\hline PROJETO: & Mestrado Lucas - & 2018 & & & & & & & & & \\
\hline REGIÃO: & São Bento do Sap & ucaí & & & & & & & & & \\
\hline PESO: & $32 \mathrm{Kg}$ & & & & & & & & & & \\
\hline TANQUE: & Pirex 25 L (1) & & & & & & & & & & \\
\hline \multicolumn{12}{|c|}{ ANÁLISES } \\
\hline${ }^{\circ} \mathrm{BRIX}$ & 22,5 & & & & & & & & & & \\
\hline DENSIDADE: & 1088 & & & & & & & & & & \\
\hline ACIDEZ TOTAL: & $94 \mathrm{meq} / \mathrm{L}$ & & & & & & & & & & \\
\hline $\mathrm{pH}:$ & 3,94 & & & & & & & & & & \\
\hline \multicolumn{12}{|c|}{ ACOMPANHAMENTO DIÁRIO DE VINIFICAÇÃO } \\
\hline DATA & HORA & DENSID. & TEMP. & DATA & HORA & DENSID. & TEMP. & DATA & HORA & DENSID. & TEMP. \\
\hline 15-Aug & $8 \mathrm{~h}$ & 1090 & 18 & & & & & & & & \\
\hline 16-Aug & $8 \mathrm{~h}$ & 1078 & 18 & & & & & & & & \\
\hline 17-Aug & $8 \mathrm{~h}$ & 1050 & 16 & & & & & & & & \\
\hline 18-Aug & $8 \mathrm{~h}$ & 1042 & 19 & & & & & & & & \\
\hline 19-Aug & $8 \mathrm{~h}$ & 1026 & 18 & & & & & & & & \\
\hline 20-Aug & $8 \mathrm{~h}$ & 1008 & 17 & & & & & & & & \\
\hline 21-Aug & $8 \mathrm{~h}$ & 1002 & 17 & & & & & & & & \\
\hline 22-Aug & $8 \mathrm{~h}$ & 998 & 19 & & & & & & & & \\
\hline 23-Aug & $8 \mathrm{~h}$ & 996 & 20 & & & & & & & & \\
\hline 24-Aug & $8 \mathrm{~h}$ & & & & & & & & & & \\
\hline & & & & & & & & & & & \\
\hline \multicolumn{12}{|c|}{ VINIFICAÇÃO } \\
\hline COLHEITA: & $13 / 08 / 2018$ & & & & & & & & & & \\
\hline DESENGACE: & $14 / 08 / 2018$ & & & & & & & & & & \\
\hline OPF: & - & & & & & & & & & & \\
\hline INÍCIO F.A. : & $14 / 08 / 2018$ & & & & & & & & & & \\
\hline FIM F.A. : & $24 / 08 / 2018$ & & & & & & & & & & \\
\hline DESCUBE: & $24 / 08 / 2018$ & & & & & & & & & & \\
\hline \multicolumn{12}{|l|}{ FML: } \\
\hline ESTABILIZAÇÃO: & 15 dias por $-5^{\circ} \mathrm{C}$ & & & & & & & & & & \\
\hline & & & & & & & & & & & \\
\hline LEVEDURA: & $25 \mathrm{~g} / \mathrm{HI}$ (Maurivir & Awri150 & & & & & & & & & \\
\hline \multicolumn{12}{|l|}{ ENZIMA: } \\
\hline \multicolumn{12}{|l|}{ CLARIFICANTE: } \\
\hline $\mathrm{SO}_{2}$ INICIAL: & $80 \mathrm{mg} / \mathrm{L}$ & & & & & & & & & & \\
\hline \multicolumn{12}{|c|}{ OBSERVAÇÕES E CORREÇÕES AO LONGO DO PROCESSO } \\
\hline \multicolumn{12}{|c|}{ Após F.M -> correção do SO2 para 35 mg/L } \\
\hline Envase -> correçã & ão do SO2 para 35 & $\mathrm{mg} / \mathrm{L}$ & & & & & & & & & \\
\hline & & & & & & & & & & & \\
\hline
\end{tabular}


RELATÓRIO DE VINIFICAÇÃo

\begin{tabular}{|c|c|c|c|c|c|c|c|c|c|c|c|}
\hline PROJETO: & \multicolumn{2}{|c|}{ Mestrado Lucas - 2018} & & & & & & & & & \\
\hline REGIÃO: & \multicolumn{2}{|c|}{ São Bento do Sapucaí } & & & & & & & & & \\
\hline PESO: & \multicolumn{2}{|l|}{$32 \mathrm{~kg}$} & & & & & & & & & \\
\hline TANQUE: & \multicolumn{2}{|l|}{ Pirex $25 \mathrm{~L}(2)$} & & & & & & & & & \\
\hline \multicolumn{12}{|c|}{ ANÁLISES } \\
\hline${ }^{\circ} B R I X:$ & \multicolumn{2}{|l|}{22,5} & & & & & & & & & \\
\hline DENSIDADE: & \multicolumn{2}{|l|}{1088} & & & & & & & & & \\
\hline ACIDEZ TOTAI & \multicolumn{2}{|l|}{$94 \mathrm{meq} / \mathrm{L}$} & & & & & & & & & \\
\hline $\mathrm{pH}:$ & \multicolumn{2}{|l|}{3,94} & & & & & & & & & \\
\hline \multicolumn{12}{|c|}{ ACOMPANHAMENTO DIÁRIO DE VINIFICAÇÃO } \\
\hline DATA & HORA & DENSID. & TEMP. & DATA & HORA & DENSID. & TEMP. & DATA & HORA & DENSID. & TEMP. \\
\hline 15-Aug & $8 \mathrm{~h}$ & 1094 & 18 & & & & & & & & \\
\hline 16-Aug & $8 \mathrm{~h}$ & 1084 & 18 & & & & & & & & \\
\hline 17-Aug & $8 \mathrm{~h}$ & 1050 & 16 & & & & & & & & \\
\hline 18-Aug & $8 \mathrm{~h}$ & 1046 & 19 & & & & & & & & \\
\hline 19-Aug & $8 \mathrm{~h}$ & 1032 & 18 & & & & & & & & \\
\hline 20-Aug & $8 \mathrm{~h}$ & 1022 & 17 & & & & & & & & \\
\hline 21-Aug & $8 \mathrm{~h}$ & 1014 & 17 & & & & & & & & \\
\hline 22-Aug & $8 \mathrm{~h}$ & 1002 & 19 & & & & & & & & \\
\hline 23-Aug & $8 \mathrm{~h}$ & 998 & 20 & & & & & & & & \\
\hline \multirow[t]{2}{*}{ 24-Aug } & & 998 & & & & & & & & & \\
\hline & & & & & & & & & & & \\
\hline \multicolumn{12}{|c|}{ VINIFICAÇÃO } \\
\hline COLHEITA: & \multicolumn{2}{|l|}{$13 / 08 / 2018$} & & & & & & & & & \\
\hline DESENGACE: & \multicolumn{2}{|l|}{$14 / 08 / 2018$} & & & & & & & & & \\
\hline OPF: & \multirow{2}{*}{\multicolumn{2}{|c|}{$\frac{-}{14 / 08 / 2018}$}} & & & & & & & & & \\
\hline INÍCIO F.A. : & & & & & & & & & & & \\
\hline FIM F.A. : & \multicolumn{2}{|l|}{$24 / 08 / 2018$} & & & & & & & & & \\
\hline DESCUBE: & \multicolumn{2}{|l|}{$24 / 08 / 2018$} & & & & & & & & & \\
\hline \multicolumn{12}{|l|}{ FML: } \\
\hline \multicolumn{12}{|c|}{ ESTABILIZAÇÃ 15 dias por -5으 } \\
\hline & & & & & & & & & & & \\
\hline LEVEDURA: & \multicolumn{3}{|c|}{ 25g/HI (Maurivin Awri1503) } & & & & & & & & \\
\hline ENZIMA: & \multicolumn{2}{|c|}{$2 \mathrm{~g} / \mathrm{hl}$ (Colorpect) } & & & & & & & & & \\
\hline \multicolumn{12}{|l|}{ CLARIFICANTE: } \\
\hline $\mathrm{SO}_{2}$ I INICIAL: & $80 \mathrm{mg} / \mathrm{L}$ & & & & & & & & & & \\
\hline \multicolumn{12}{|c|}{ OBSERVAÇÕES E CORREÇÕES AO LONGO DO PROCESSO } \\
\hline Após F.M ->cc & orreção do SO2 & para $35 \mathrm{~m}$ & & & & & & & & & \\
\hline Envase -> corr & reção do SO2 pa & ara $35 \mathrm{mg} /$ & & & & & & & & & \\
\hline & & & & & & & & & & & \\
\hline & & & & & & & & & & & \\
\hline
\end{tabular}


RELATÓRIO DE VINIFICAÇÃO

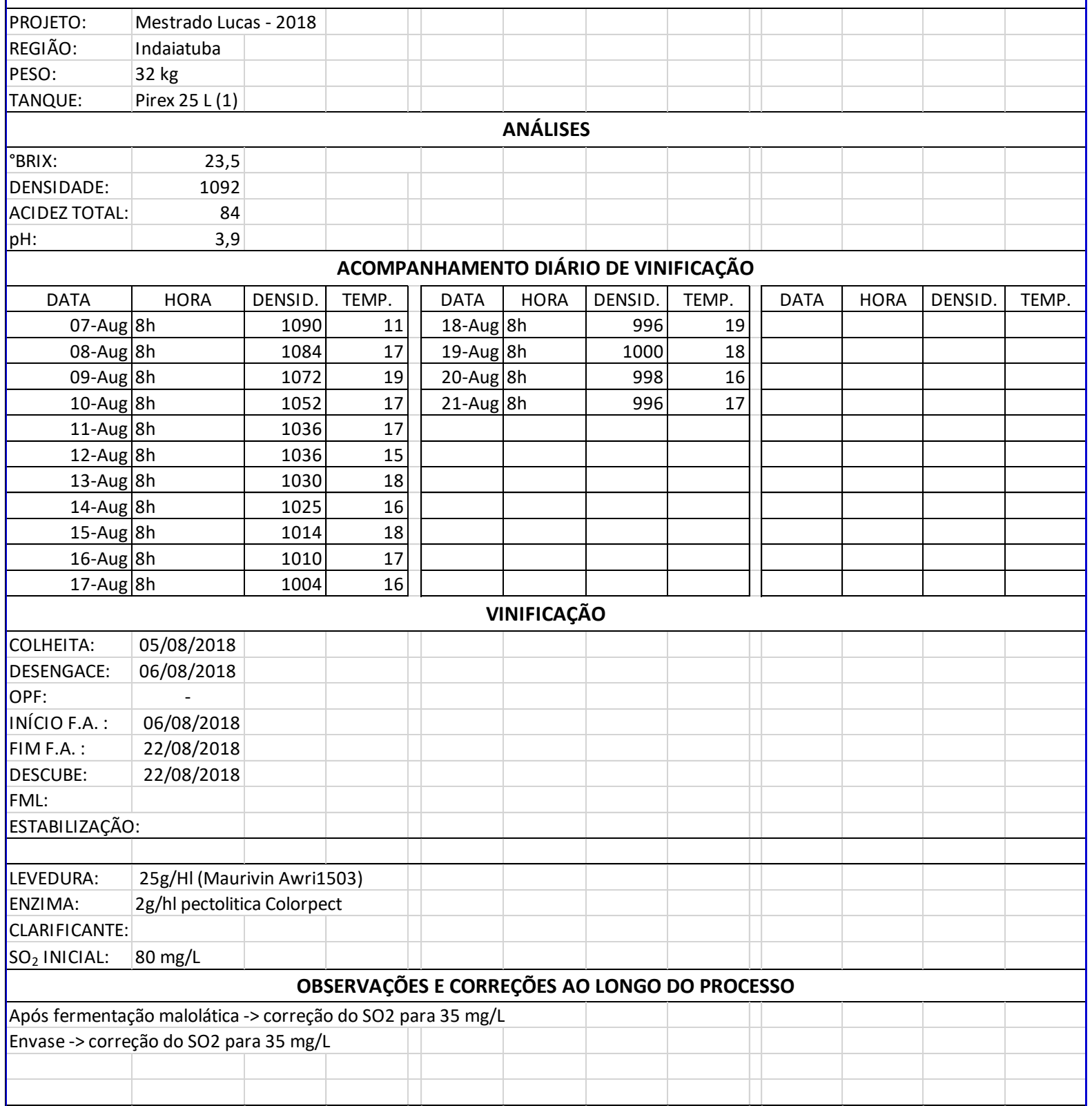




\begin{tabular}{|c|c|c|c|c|c|c|c|c|c|c|c|}
\hline 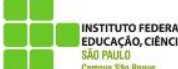 & 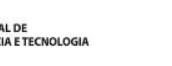 & & & RELATÓRIC & O DE VII & IFICAÇÃO & & & & & \\
\hline PROJETO: & Mestrado Luca & as - 2018 & & & & & & & & & \\
\hline REGIÃO: & Indaiatuba & & & & & & & & & & \\
\hline PESO: & $32 \mathrm{~kg}$ & & & & & & & & & & \\
\hline TANQUE: & Pirex $25 \mathrm{~L}(2)$ & & & & & & & & & & \\
\hline \multicolumn{12}{|c|}{ ANÁLISES } \\
\hline 'BRIX: & 23,5 & & & & & & & & & & \\
\hline DENSIDADE: & 1092 & & & & & & & & & & \\
\hline ACIDEZ TOTAL: & 84 & & & & & & & & & & \\
\hline pH: & 3,9 & & & & & & & & & & \\
\hline \multicolumn{12}{|c|}{ ACOMPANHAMENTO DIÁRIO DE VINIFICAÇÃO } \\
\hline DATA & HORA & DENSID. & TEMP. & DATA & HORA & DENSID. & TEMP. & DATA & HORA & DENSID. & TEMP. \\
\hline 07-Aug & $8 \mathrm{~h}$ & 1092 & 11 & 18-Aug 8 & $8 \mathrm{~h}$ & 1002 & 19 & & & & \\
\hline 08-Aug & $8 \mathrm{~h}$ & 1086 & 17 & 19-Aug 8 & $8 \mathrm{~h}$ & 100 & 18 & & & & \\
\hline 09-Aug & $8 \mathrm{~h}$ & 1068 & 19 & 20 -Aug 8 & $8 \mathrm{~h}$ & 998 & 16 & & & & \\
\hline 10-Aug & $8 \mathrm{~h}$ & 1054 & 17 & 21-Aug 8 & $8 \mathrm{~h}$ & 994 & 17 & & & & \\
\hline 11-Aug & $8 \mathrm{~h}$ & 1040 & 17 & & & & & & & & \\
\hline 12-Aug & $8 \mathrm{~h}$ & 1040 & 15 & & & & & & & & \\
\hline 13-Aug & $8 \mathrm{~h}$ & 1036 & 18 & & & & & & & & \\
\hline 14-Aug & $8 \mathrm{~h}$ & 1026 & 16 & & & & & & & & \\
\hline 15-Aug & $8 \mathrm{~h}$ & 1018 & 18 & & & & & & & & \\
\hline 16-Aug & $8 \mathrm{~h}$ & 1012 & 17 & & & & & & & & \\
\hline 17-Aug & $8 \mathrm{~h}$ & 1008 & 16 & & & & & & & & \\
\hline \multicolumn{12}{|c|}{ VINIFICAÇÃO } \\
\hline COLHEITA: & $05 / 08 / 2018$ & & & & & & & & & & \\
\hline DESENGACE: & $06 / 08 / 2018$ & & & & & & & & & & \\
\hline OPF: & - & & & & & & & & & & \\
\hline INÍCIO F.A.: & 06/08/2018 & & & & & & & & & & \\
\hline FIM F.A. : & $22 / 08 / 2018$ & & & & & & & & & & \\
\hline DESCUBE: & $22 / 08 / 2018$ & & & & & & & & & & \\
\hline FML: & & & & & & & & & & & \\
\hline \multicolumn{12}{|l|}{ ESTABILIZAÇÃO: } \\
\hline & & & & & & & & & & & \\
\hline LEVEDURA: & \multicolumn{3}{|c|}{ 25g/HI (Maurivin Awri1503) } & & & & & & & & \\
\hline ENZIMA: & \multicolumn{3}{|c|}{$2 \mathrm{~g} / \mathrm{hl}$ pectolitica Colorpect } & & & & & & & & \\
\hline \multicolumn{12}{|c|}{ CLARIFICANTE: } \\
\hline $\mathrm{SO}_{2}$ INICIAL: & $80 \mathrm{mg} / \mathrm{L}$ & & & & & & & & & & \\
\hline \multicolumn{12}{|c|}{ OBSERVAÇÕES E CORREÇÕES AO LONGO DO PROCESSO } \\
\hline \multicolumn{12}{|c|}{ Após fermentação malolática -> correção do SO2 para 35 mg/L } \\
\hline Envase -> corre & ção do SO2 par & $35 \mathrm{mg} / \mathrm{L}$ & & & & & & & & & \\
\hline & & & & & & & & & & & \\
\hline & & & & & & & & & & & \\
\hline
\end{tabular}




\section{2 - Anexo 2}

HeatMap mosto 2017

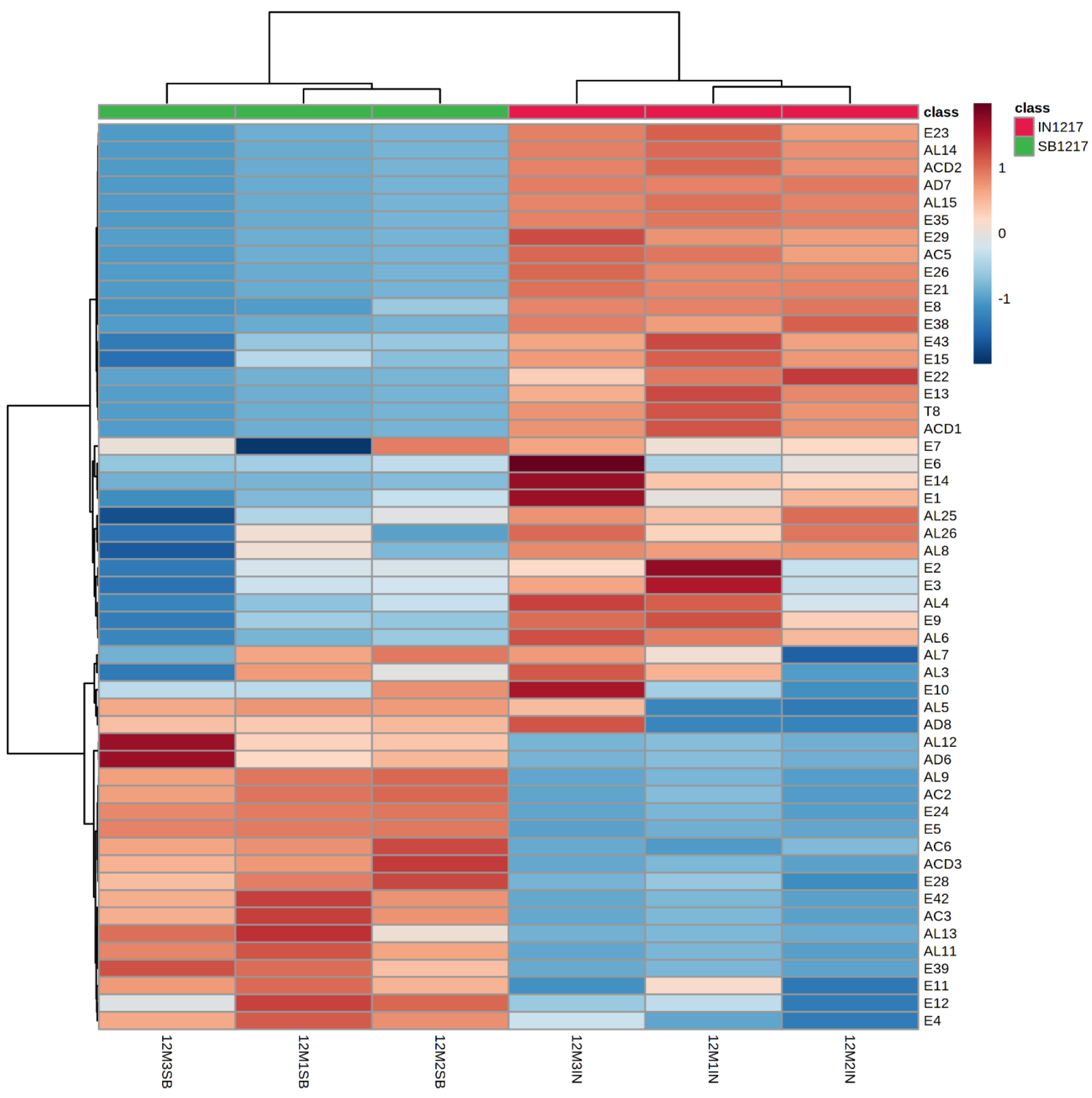


HeatMap mosto 2018

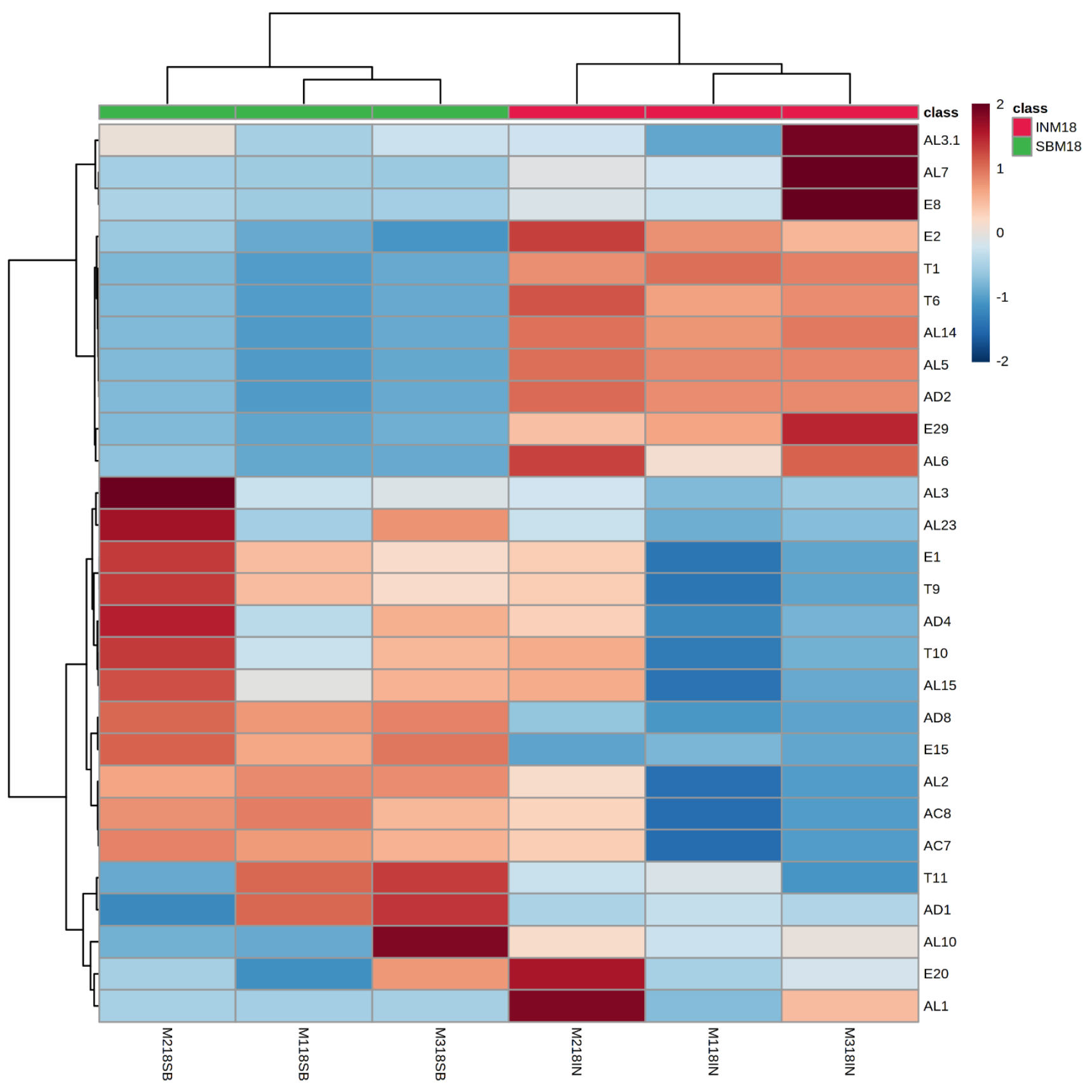


HeatMap envase 2017

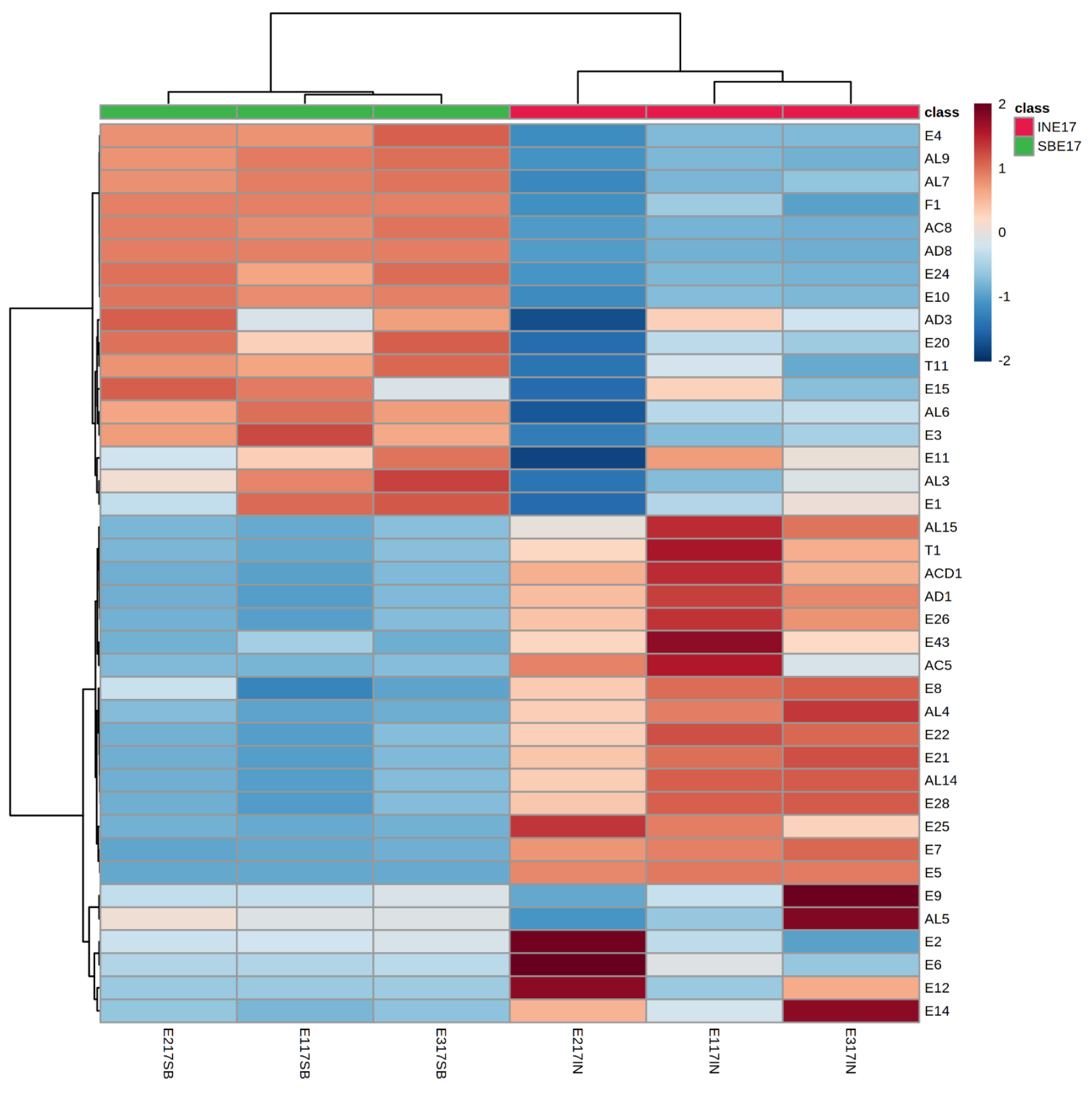


HeatMap envase 2018

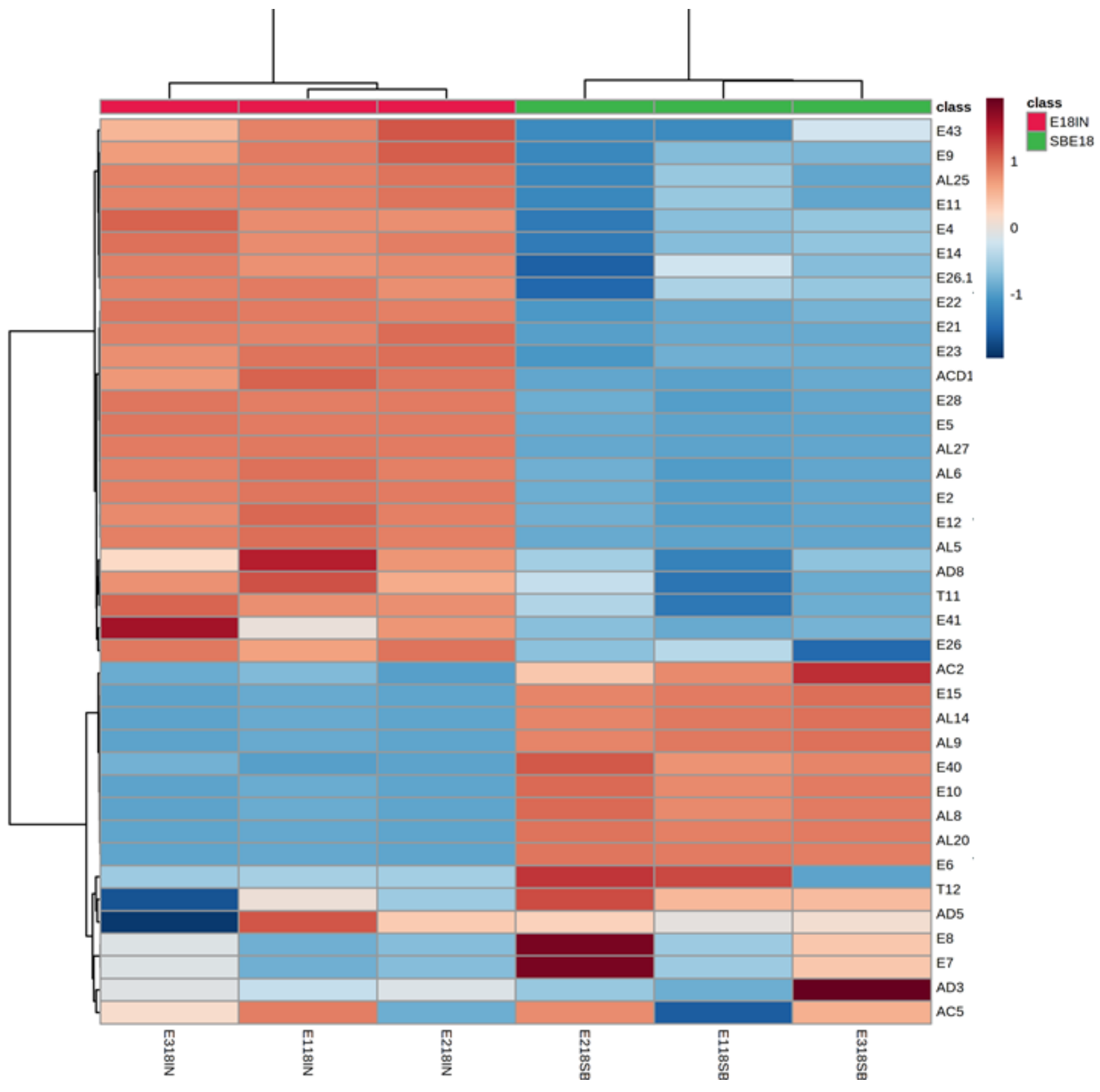


Heatmap 12 meses 2017

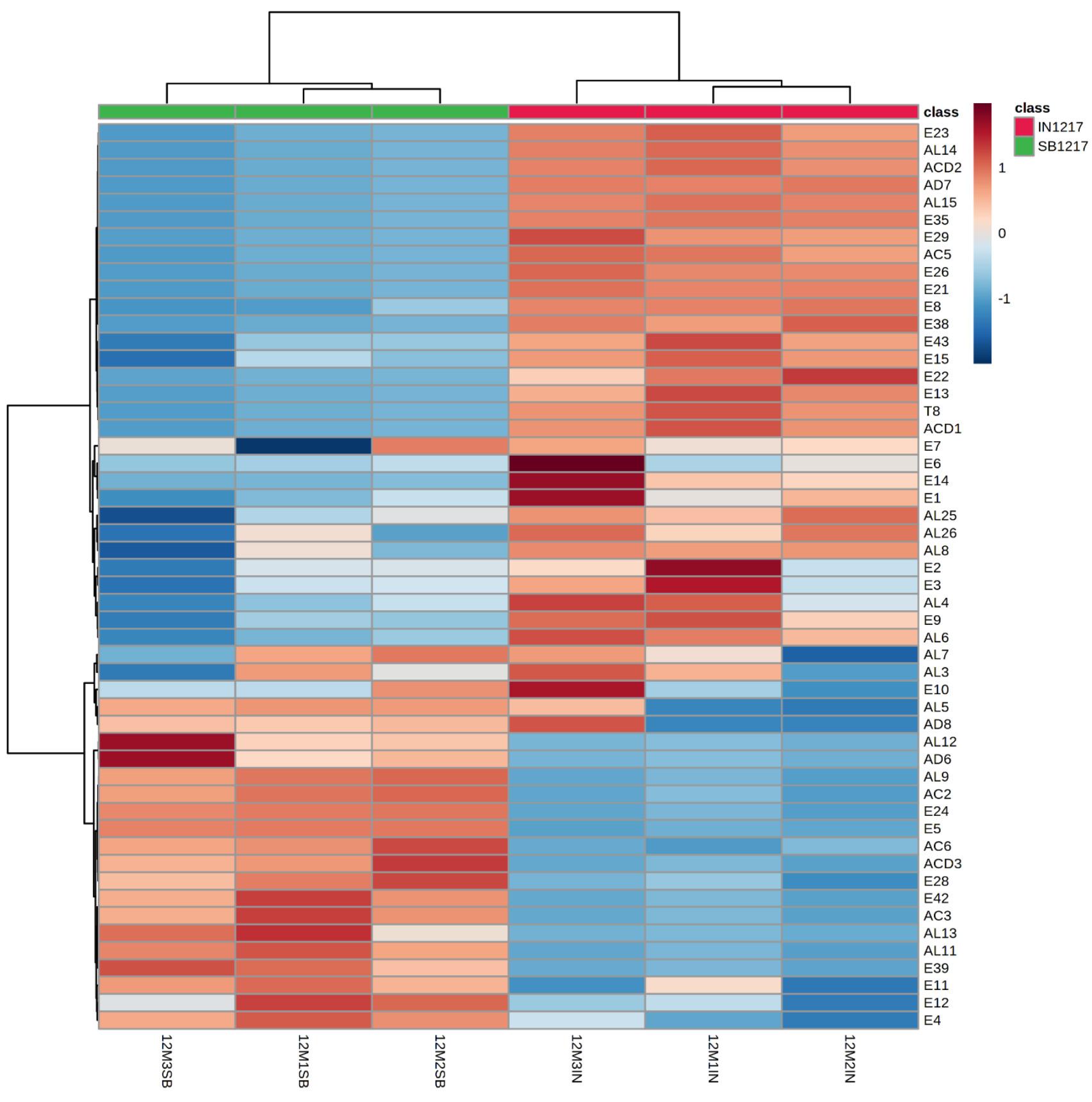


HeatMap 12 meses 2018

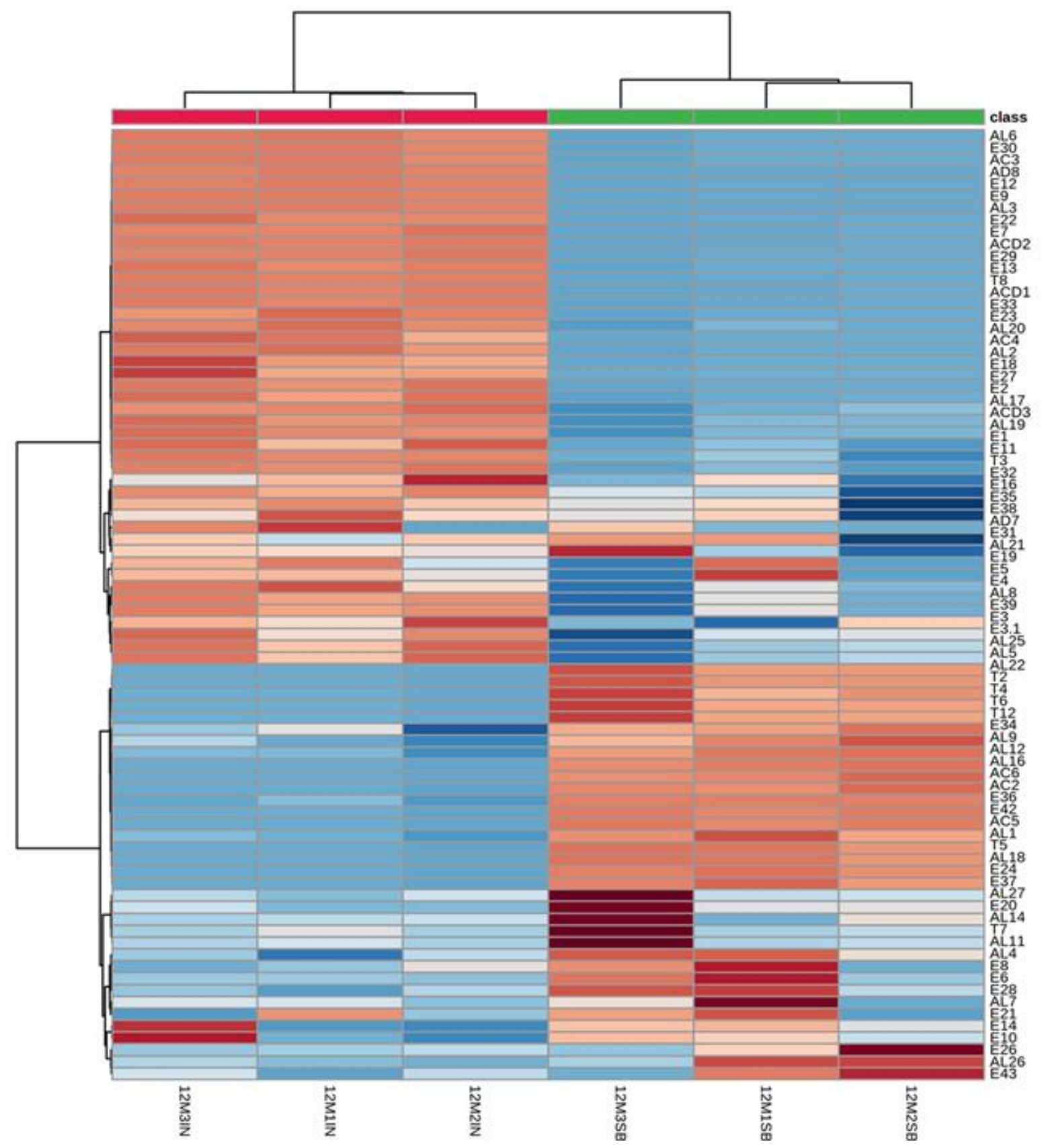




\section{7 - REFERÊNCIAS BIBLIOGRAFICA}

A.C. NOBLE, R.A. FLATH, R.R. FORREY, J. Agric. Food Chem. 28,346, 1980.

AHMED, W. M.; NIJSEN T. M. N.; GOODACRE R.; FOWLER S. J. Exhaled Volatile Organic Compounds of Infection: A Systematic Review. ACS Infect. Dis. 2017, 3, 10, 695-710 Publication Date:September 4, 2017.

AGOSIN, E. Potencial aromático de las principales variedades de uva cultivadas en climas cálidos: el caso de Sudamérica. ACE: Revista de enología, ISSN-e 16974123, №. 134, 2013.

AGOSIN, E.; BELANCIC, A. Aromatic potential of certain Muscat grape varieties important for Pisco production in Chile. Am J. Enol. Vitic, 2000.

AMORIN, D. A.; FAVERO, A.C.; REGINA, M.A. Produções extemporânea da videira, cultivar Syrah, nas condições do sul de Minas Gerais. Revista Brasileira de Fruticultura, Jaboticabal, v. 27, n.2 p. 327-331, 2005.

AMORIN, D. A.; RegINA, M. A.; FÁVERO, A. C.; MOtA, R. V.; PEREIRA, G. E. Elaboração de vinho tinto fino. Informe agropecuário. Belo Horizonte, v.27, . 124, p.65-76. 2006.

ANTALICK, G.; ŠUKLJE, K.; BLACKMAN, J.W.; MEEKS, C.; DELOIRE, A.; SCHMIDTKE, L.M. Influence of grape composition on red wine ester profile: comparison between Cabernet Sauvignon and Shiraz cultivars from Australian warm climate. Journal, 2015.

AWRI - The Australian Wine Research Institute. Achieving successful malolactic fermentation. Australia, 2016. Disponível em <https://www.awri.com.au/wpcontent/uploads/2011/06/Malolactic-fermentation.pdf> acesso 10/05/2019.

BELANCIC, A. Y E. AGOSIN. 2002. Aromas varietales: Influencia de ciertas prácticas vitícolas $\mathbf{y}$ enológicas. Disponible en: http://www.recursosdeenologia.com/rec/23/aromas-varietales-influenciade-ciertaspracticas-viticolas-y-enologicas/. Acesso em 08 de maio de 2019. 
BENZ M.J., ANDERSON M.M., WILLIAMS M.A., BARNHISEL K. and WOLPERT J.A. Viticultural performance of five Merlot clones in Oakville, Napa Valley. Am. J. Enol. Vitic., 57, 233-237, 2006.

BLOUIN J. and GUIMBERTEAU G. Principales components de la uva y evolución durante la maduración, 57-100. In: Maduracion y madurez de la uva. Ed. MundiPrensa, Madrid, p. 151, 2004.

BNDES Setorial. Desafio da viticultura brasileira. Rio de Janeiro, n. 19, p. 67-90, mar. 2004.

BOLETIN 200 INSTITUTO AGRONÔMICO DE CAMPINAS. Disponivel em: http://www.iac.sp.gov.br/areasdepesquisa/frutas/frutiferas_cont.php?nome=Uvas. Acesso: 12/10/2020.

BRILLANTE, L.; MARTÍNEZ-LÜSCHER, J.; KAAN KURTURAL, S. Applied water and mechanical canopy management affect berry and wine phenolic and aroma composition of grapevine (Vitis vinifera L., cv. Syrah) in central California. Scientia Horticulturae 227: 261-271, 2018.

CÂMARA, J. S.; ALVES, A.; MARQUES, J. C. Multivariate analysis for the classification and differentiation of Madeira wines according to main grape varieties. Talanta, v. 68, p. 1512-1521, 2006.

CAMARGO, U.A. Variedades de uva. In: GUERRA, C.G.; MANDELLI, F.; TONIETTO, J.; ZANUS, M.C.; CAMARGO, U.A. Conhecendo o essencial sobre uvas e vinhos. Bento Gonçalves: Embrapa Uva e Vinho, 2009.

CAMARGO, U.A.; TONIETTO, J.; HOFFMANN, A. Progresso na viticultura brasileira. Rev. Bras. Frutic., Jaboticabal - SP, Volume Especial, E. 144-149, Outubro 2011.

CARBONNEAU, A. La viticulturetropicalemondiale. ProgrésAgricole et Viticole, Montpellier, 127. p. 281- 283. 2010. 
CONCEIÇÃO, M. A. F.; TONIETTO, J. Potencial climático para a produção de uvas para a elaboração de vinhos finos no norte de Minas Gerais. Revista Brasileira de Fruticultura, Jaboticabal, v. 27, 2005.

CONDE, C., SILVA, P., FONTES, N., DIAS, A. C. P., TAVARES, R. M., SOUSA, M. J., AGASSE, A., DELROT, S., \& GERÓS, H. Biochemical changes throughout grape berry development and fruit and wine quality. Global Science Books, 1(1), $1-22,2007$.

CONDURSO, C.; CINCOTTA, F.; TRIPODI, G.; SPARACIO, A.; GIGLIO, D. M. L.; SPARLA, S.; VERZERA, A. Effects of cluster thinning on wine quality of Syrah cultivar (Vistis vinifera L.) Eur Food Res Technol 242:1719-1726, 2016.

COPELLO, M. Brasil, mercado em ebulição. Revista Vinhos do Brasil. Rio de Janeiro. p.34- 37. 2015

DAL'OSTO, M. C.; BASSI, A. P.; MELO, R. T.; AMARAL, A. L.; DAL'OSTO, M. F. Caracterização química e sensorial das variedades, Malbec, Cabernet Saauvignon, e Cabernet Franc com colheita de inverno para elaboração de vinhos finos de qualidade em São Roque - SP. SCIENTIA VITAE, v.4, n.13. São Roque, 2016.

DAL'OSTO, M. C.; ROMBALDI, C.; PURGATTO, E.; AMARAL, L. B; PAZ, N.; TANNURE, L.; DAL'OSTO, M. Syrah wine from são paulo's high lands - brazil, chemical and sensorial characterization, with an extemporaneous production cycle. GIESCO: Mendonza, 2017.

DAL'OSTO, M.; MOTTA, R.V. Emprego de baixas temperaturas na extração de compostosfenólicos durante a elaboração de vinhos Syrah. Revista Brasileira de Viticultura e Enologia, n4, p. 36-44. 2012.

DIAS, F. A. N. . Rootstock on vine performance and wine quality of 'Syrah' under double pruning management. Scientia Agricola, v. 74, p. 134-141, 2017

ENTAV. Catalogue desvariétés et clones de vignecultivésen France. Grau duRoi, p. 357, 1995. 
FAVERO, A. C.; AMORIN, D. A.; MOTA, R. V.; SOARES, A. M.; REGINA, M. A. Viabilidade de produção da videira Syrah, em ciclo de outono-inverno na região sul de Minas Gerais. Ver. Bras. Frutic.,30,685-690, 2008.

FLANZY, C.;Enologia: Fundamentos científicos y tecnológicos.Paris: Technique et documentation,. p.783, 2000

FRANK, S.; WOLLMANN, N.; SCHIEBERLE, P.; HOFMANN, T. Reconstitution of the flavor signature of Dornfelder red wine on the basis of the natural concentrations of its key aroma and taste compounds. J. Agric. Food Chem. 59, 8866-8874,2011.

GIOVANNINI, E. Manual de Viticultura. Porto Alegre: Editora Bookman, 2014.

GIOVANNINI, E; MANFROI, V. Viticultura e Enologia. Bento Golçalves:IFRS. $2^{\mathrm{a}}$ edição. 2013

GÓMEZ-MíGUEZ, M.;GÓMEZ-MíGUEZ, J.; VICARIO, I. M.;HEREDIA,F. J. Assessment of colour and aroma in white wines vinifications: Effects of grape maturity and soil type. J. of Food Engineering. 79. 758-764. 10.1016, 2007.

GONZÁLEZ-BARREIRO C., RIAL-OTERO R., CANCHO-GRANDE B., SIMALGÁRDARA J. Wine aroma compounds in grapes: A critical review. Crit. Rev. Food Sci., 55, 202-218, 2015.

GRIS, E. F.; BURIN, V. M.; BRIGHENTI, E.; VIEIRA, H.; BORDIGNON-LUIZ, M. T. Phenology and ripening of Vitis vinifera L. grape varieties in São Joaquim, southern Brazil: a new South American wine growing region. Cien. Inv. Agr. 37(2):61-75. 2010

HASSIMOTTO, N. M. A, MOTA, R. V, CORDENUNSI, B. R. LAJOLO, F. M. Physicochemical characterization and bioactive compounds of blackberry fruits (Rubus sp.) grown in Brazil Ciências Tecnologia Alimentos, Campinas, 28, v.3. pg: 702-708, jul.-set. 2008.

HUNTER, J. J., \& VOLSCHENK, C. G. Chemical composition and sensory properties of non-wooded and wooded Shiraz (Vitis vinifera L.) wine as affected 
by vineyard row orientation and grape ripeness level. Journal of the Science of Food and Agriculture, 98(7), 2689-2704, 2018.

IBRAVIN. Cartilha de vinhos do Brasil. Ed 2 -Bento Gonçalves, RS, 2016.

ILC T., WERCK-REICHHART D., NAVROT N. Meta-analysis of the core aroma components of grape and wine aroma. Front. Plant Sci., 7, 1-15, 2016.

JACKSON D.I. and LOMBARD P.B. Environmental and management practices affecting grape composition and wine quality - a review. Am. J. Enol. Vitic., 44, 409-430,1993.

JIANG, B. AND ZHANG, Z. Volatile Compounds of Young Wines from Cabernet Sauvignon, Cabernet Gernischet and Chardonnay Varieties Grown in the Loess Plateau Region of China. Molecules 15, 9184-9196, 2010.

JUNIOR, A. P.; NETO, F. J.; SILVA, M. J. R.; TECCHIO M. A. Produção, qualidade e maturação da uva "syrah" em condição subtropical do Brasil. Brazilian Journal of Biosystems Engineering v. 13(1):72-79, 2019.

LINS, A. D. L.; ROQUE, I. M. B.; LISBÔA, C. G. C.; FEITOSA, R. M.; COSTA, J. D. S. Qualidade durante o desenvolvimento de uvas viníferas 'Syrah' do Submédio do Vale São Francisco. Revista AGROTEC, v. 36, n. 1, p. 259-263, 2015.

LIU, S.; LAAKSONEN, O. and YANG, B. Volatile composition of bilberry wines fermented with non-Saccharomyces and Saccharomyces yeasts inpure,sequential and simultaneousi noculations. Food Microbiology 80 25-39, 2018.

MARIE, A. S.; BAUMES, R. L.; LANGLOIS, D.; RIOU, C.; RAZUNGLES, A. J. Role of glycosidic aroma precursors on the odorant profiles of grenache noir and syrah wines from the rhone valley. Part 2: characterisation of derived compounds. J. Int. Sci. Vigne Vin, 43, n4 , 213-223,2009.

MARIN, F. Z. Elaboracíon y crianza del vino tinto: Aspectos científicos y práticos. A madrid Vicent ediciones. Ed.1, 224 p., Madri, 2003. 
MAYR, C. M.; GEUE, J. P.; HOLT, H. E.; PEARSON, W. P.; JEFFERY, D. W.; FRANCIS, L. Characterization of the Key Aroma Compounds in Shiraz Wine by Quantitation, Aroma Reconstitution, and Omission Studies. J. Agric. Food Chem., $62,4528-45,2014$.

McCORD, J.D., TROUSDALE, E., RYU, D.D.Y. An improved sample preparation procedure for the analysis of major organic compounds in grape must and wine by high performance liquid chromatography. American Journal of Enology and Viticulture, Davis v.35, p.28-29, 1984.

MELLO, L. M. R. Panorama da produção de uvas e vinhos no Brasil. Campo e negócios. Rio Grande do Sul, 2017.

MOTA, R. V.REGINA, M. A.; CHALFUN, N. N. J.. Viabilidade de produção da videira Syrah em ciclos de verão e inverno no sul de Minas Gerais. 2007.

MOTA, R. V.; FAVERO, A. C.; SILVA, C. P. C.; PURGATtO, E.; SHIGA, T. M.; REGINA, M. A. Wine grape quality of grapevines grown in the cerrado ecoregion of Brazil. J. Int. Sci. Vigne Vin, 45, n², 101-109, 2011.

MOTA, R.V.; SILVA, C. P. C.; FAVERO, A. C.; PURGATTO, E.; SHIGA, T. M.; REGINA, M. A. Composição físico-química de uvas para vinho fino em ciclos de verão e inverno. Revista Brasileira de Fruticultura, Jaboticabal, v.32, p. 1127-1137, 2010.

MOTA, R. V. ; PEREGRINO, I. ; RIVERA, S.P.T. ; HASSIMOTTO, N. M. A. ; SOUZA, A.L. ; SOUZA, C. R. . Characterization of Brazilian Syrah winter wines at bottling and after ageing. SCIENTIA AGRICOLA, v. 78, p. e20190233, 2020.

ORLANDO, T. G. S.; JÚNIOR, M. J. P.; SANTOS, A. O.; HERNANDES, J. L. Comportamento das cultivares Cabernet Sauvignone e Syrah em diferentes porta-enxertos. Ciênc. agrotec., Lavras, v. 32, n. 3, p. 749-755, maio/jun., 2008.

PALIYATH, G.; MURR, D. Biochemistry of Fruits. Postharvest Biology and Technology of Fruits, Vegetables, and Flowers, v. 03, p. 19-50, 2008. 
PÉREZ, A.G.; SANZ, C. Formation of fruit flavor. In: Bruckner, B.; Wyllie, S. G. Fruit and Vegetable Flavour- Recent Advances ans Future Prospects. Woodhead Publishing. Cap. 4, pag. 41-70, 2008.

PISCIOTTA, A., DI LORENZO, R., BARBAGALLO, M.G. \& HUNTER, J.J. Berry characterisation of cv. Shiraz according to position on the rachis. S. Afr. J. Enol. Vitic. 34(1), 100-107, 2013.

PROTAS, J. F. da S.; CAMARGO, U. A.; MELLO, L. M. R. de. Vitivinicultura brasileira: regiões tradicionais e pólos emergentes. Informe Agropecuário, Belo Horizonte,v. 27, n. 234, p. 7-15, 2006.

RAPOSO, R.; RUIZ-MORENO, M. J.; GARDE-CERDÁN, T.; PUERTAS, B.; MORENO-ROJAS, J. M.; GONZALO-DIAGO, A.; GUERRERO, R.; ORTIZ, V.; CANTOS-VILLAR, E. Grapevine-shoot stilbene extract as a preservative in red wine. Food Chemistry, vol 197, pag 1102-1111, 2016.

RIBÉREAU-GAYON, J.; GLORIES, Y.; MAUJEAN, A.; DUBOURDIEU, D. Traité d'oenologie: chimie du vin - stabilisation et traitements. 5.ed. Paris: DUNOD. v.2, 566p, 2004.

RIBEIRO, T. P.; LIMA, M. A. C.; ALVES, R. E.; GONÇALVES, A. L. S.; SOUZA, A. P. $C$. Chemical characterization of winemaking byproducts from grape varieties cultivated in Vale do São Francisco, Brazil. Food Sci. Technol, Campinas, 38(4): 577-583, Oct.-Dec. 2018.

RIZZON L.A. and MIELE A. Avaliação da cv. Cabernet Sauvignon para elaboração de vinho tinto. Ciênc. Tecnol. Aliment., 22, 192-198, 2002.

SABON, I.; DE REVEL, G.; KOTSERIDIS, Y. AND BERTRAND, A. Determination of volatile compounds in Grenache wines in relation with diferent terroirs in the Rhone Valey. J. Agric. Food Chem. 50:6341-6345, 2002.

SANTOS, J. S. São Roque de Outrora. São Roque: O Democrata, 1938. 
SELLI, S., T. CABAROGLU, A. CANBAS, H. ERTEN, C. NURGEL, J.P. LEPOUTRE, AND Z. GUNATA. "Volatile Composition of Red Wine from Cv. Kalecik Karası Grown in Central Anatolia." Food Chemistry 85, no. 2, 2004.

SENER, H. Effect of Temperature and Duration of Maceration on Colour and Sensory Properties of Red Wine - A Review. S. Afr. J. Enol. Vitic., Vol. 39, No. 2, 2018.

SILVA, T. G. Diagnóstico vitivinícola do Sul de Minas Gerais. 196 p. dissertação (Mestrado em fitotecnia) - Universidade Federal de Lavras, Lavras, 1998

TOGORES, H. J.; Tratado de enologia; Madri, ed.2, 2011.

UVIBRA, 2012. Disponível em: Acesso 4 de junho de 2019.

VAN LEEWEN, C.; FRIANT, P.; CHONÉ, X.; TREGOAT, O.; KOUNDOURAS, S.; DUBORDIEU, D. Influence of climate, soil, and cultivar on terroir. Am. J. Enol. Vitic. 55:3, 2004.

VERDI, A. R.; OTANI, M. N. Vitivinicultura do Estado de São Paulo (Brasil): estratégias de governança e tecnológicas frente aos desafios do mercado. 39 th OIV Congress, Brazil 2016.

VERDI, A. R.; OTANI, M. N.; MAIA M. L.; FREDO, C. E.; OLIVEIRA, A. L. R.; HENANDES, J. L. Panorama da vitivinicultura paulista, censo 2009. Informações Econômicas, SP, v. 41, n. 11, nov. 2011

VILANOVA, M., ZAMUZ, S., VILARIÑO, F., \& SIEIRO, C. Effect of terroir on the volatiles of Vitis vinifera cv. Albariño. Journal of the Science of Food and Agriculture, 87(7), 1252-1256. http://dx.doi. org/10.1002/jsfa.2833, 2007.

Weldegergis, B. T., Villiers, A., McNeish, C., Seethapathy, S., Mostafa, A., Górecki, T., \& Crouch, A. M. Characterisation of volatile components of Pinotage wines using comprehensive two-dimensiona gas chromatography coupled to time-offlight mass spectrometry (GC × GC-TOFMS). Food Chemistry, 129(1), 2011. 